\title{
Representações discursivas da mídia sobre a privatização das telecomunicações
}

\author{
Patricia Ayumi Hodge 1 \\ Cláudia Freitas ${ }^{2}$ \\ Alessandra de Sá Mello da Costa 1 \\ 1 Pontifícia Universidade Católica do Rio de Janeiro / IAG - Escola de Negócios, Rio de Janeiro / RJ - Brasil \\ 2 Pontifícia Universidade Católica do Rio de Janeiro / PPGEL - Departamento de Letras, Rio de Janeiro / RJ - Brasil
}

O artigo analisa a representação discursiva da mídia escrita hegemônica sobre a privatização das telecomunicações no Brasil. Desde a redemocratização política no país, a privatização de empresas estatais permanece na pauta de governos de diferentes posições ideológicas. Assumindo a grande imprensa como uma das principais influenciadoras da opinião pública, analisamos um corpus de 869 artigos de jornais de grande circulação e o comparamos a 344 artigos de mídias pró e antiprivatização. A análise, quantitativa e qualitativa, mostrou como a imprensa restringe o campo lexical das privatizações às empresas e aos negócios, sugerindo o discurso de que as telecomunicações são como qualquer outro negócio e tornando desnecessária sua discussão com a sociedade. A análise das principais colocações também mostrou como a privatização vem sendo representada como um marco histórico. A pesquisa contribui de duas maneiras para a administração pública e para os estudos organizacionais: traz uma materialidade para a discussão acerca das representações da privatização e apresenta uma metodologia de análise discursiva com base em grandes coleções de documentos.

Palavras-chave: privatização; telecomunicações; discurso; mídia; corpus linguistics.

\section{Representaciones discursivas de los medios de comunicación acerca de la privatización de las telecomunicaciones}

El artículo analiza la representación discursiva de los medios escritos hegemónicos sobre la privatización de las telecomunicaciones en Brasil. Desde la redemocratización política del país, la privatización de las empresas estatales ha permanecido en la agenda de los gobiernos de diferentes posiciones ideológicas. Asumiendo que la prensa convencional es uno de los principales influenciadores de la opinión pública, analizamos un corpus de 869 artículos de periódicos de amplia circulación y lo comparamos con 344 artículos de medios pro y antiprivatización. El análisis, cuantitativo y cualitativo, mostró cómo la prensa restringe el campo léxico de la privatización a empresas y negocios, sugiriendo el discurso de que las telecomunicaciones son como cualquier otro negocio y haciendo innecesaria su discusión con la sociedad. El análisis de las principales colocaciones también mostró cómo la privatización ha sido representada como un hito histórico. La investigación contribuye de dos maneras a la administración pública y a los estudios organizacionales: aporta materialidad a la discusión sobre las representaciones de la privatización y presenta una metodología de análisis discursivo basada en grandes colecciones de documentos.

Palabras clave: privatización; telecomunicaciones; discurso; medios de comunicación; lingüística de corpus.

\section{Discursive media representations on telecommunications privatization}

This paper analyzes the discursive representation of the hegemonic written media on the privatization of telecommunications in Brazil. Since the country's political re-democratization, the privatization of state-owned companies has remained on the agenda of governments from different ideological positions. Assuming the mainstream media as one of the leading influencers of public opinion, we analyzed a corpus of 869 articles from widely circulated newspapers and compared it to 344 articles in pro and anti-privatization media. The quantitative and qualitative analysis showed how the press restricts the lexical field of privatization to companies and businesses, suggesting the discourse that telecommunications is like any other business, which renders its discussion with society unnecessary. The analysis of the main collocations also showed how privatization has been represented as a historic landmark. The research contributes in two ways to public administration and organizational studies: it brings materiality to the discussion about the representations of privatization and presents a methodology of discursive analysis based on extensive collection of documents.

Keywords: privatization; telecommunications; discourse; media; corpus linguistics. 


\section{INTRODUÇÃO}

O debate sobre a privatização, aqui definida como o uso do setor privado para a provisão de um bem ou serviço público, permanece na pauta do governo brasileiro desde antes da redemocratização do país, em 1985, como mostram os principais marcos por mandato presidencial detalhados no Quadro 1. Desde então, a gestão e a operação de serviços públicos de diferentes setores vêm sendo passadas para o setor privado, seja sob a forma de venda de empresas estatais, seja sob a forma de concessão, com o discurso da melhoria da gestão, da eficiência e dos serviços prestados por essas empresas, aliado ao objetivo de fazer caixa aos cofres públicos (Almeida, 2014). Nos recentes governos dos presidentes Michel Temer (2016-2018) e Jair Bolsonaro (2019-), a privatização ainda se mostra em voga como forma de reduzir o papel do Estado e seu déficit fiscal (Esposito, 2017; Fernandes \& Tomazelli, 2019; Época, 2019), embora não sem polêmica e contestação (Lacerda, 2020; Resende, 2019).

\section{QUADRO 1 PRIVATIZAÇÕES NO BRASIL DE 1980 A 2015}

\begin{tabular}{|c|c|c|}
\hline Período & Governo & Destaques \\
\hline 1980 & $\begin{array}{l}\text { João } \\
\text { Figueiredo/ } \\
\text { José Sarney }\end{array}$ & $\begin{array}{l}\text { - Objetivo das privatizações é evitar a ampliação da presença do governo no setor produtivo. } \\
\text { - Privatização de empresas de pequeno porte que haviam sido nacionalizadas em razão de } \\
\text { dificuldades financeiras. }\end{array}$ \\
\hline 1990-1992 & Fernando Collor & $\begin{array}{l}\text { - Criação do Programa Nacional de Desestatização (PND), como parte do programa de reformas } \\
\text { econômicas do governo. } \\
\text { - Empresas visadas: estatais produtivas nos setores de siderurgia, petroquímica e de fertilizantes } \\
\text { (ex. Usiminas). } \\
\text { - Prioridade para o ajuste fiscal, sendo utilizadas na compra das empresas títulos representativos } \\
\text { da dívida pública federal ("moedas da privatização"). }\end{array}$ \\
\hline 1993-1994 & Itamar Franco & $\begin{array}{l}\text { - Conclusão da desestatização do setor siderúrgico (venda da CSN), com uso tanto de moeda } \\
\text { corrente quanto de "moedas de privatização". } \\
\text { - Eliminação da discriminação contra investidores estrangeiros, permitindo sua participação em } \\
\text { até } 100 \% \text { do capital votante das empresas a serem alienadas. }\end{array}$ \\
\hline 1995-2002 & $\begin{array}{l}\text { Fernando } \\
\text { Henrique } \\
\text { Cardoso }\end{array}$ & $\begin{array}{l}\text { - PND como um dos principais instrumentos de reforma do Estado. } \\
\text { - Criação do Conselho Nacional de Desestatização (CND) e conclusão da privatização das } \\
\text { estatais do segmento industrial. } \\
\text { - Início do processo de desestatização de empresas estaduais. } \\
\text { - Início da privatização de empresas de serviços públicos (infraestrutura) sob a forma de } \\
\text { concessões, com o argumento de melhoria da qualidade desses serviços à sociedade, } \\
\text { incluindo os setores de eletricidade, transporte e telecomunicações. } \\
\text { - Exemplos de empresas privatizadas: Companhia Vale do Rio Doce (CVRD), as } 12 \text { holdings } \\
\text { criadas com a cisão de Telebrás, Gerasul, RFSA, Banco Meridional do Brasil S/A, Datamec e } \\
\text { os Bancos Estaduais (federalizados) de São Paulo (Banespa) e de Goiás (BEG). }\end{array}$ \\
\hline 2003-2010 & $\begin{array}{l}\text { Luiz Inácio Lula } \\
\text { da Silva }\end{array}$ & $\begin{array}{l}\text { - Privatizados o Banco do Estado do Maranhão (BEM) e o Banco do Estado do Ceará (BEC). } \\
\text { - Prioridade às parcerias público-privadas e às concessões. } \\
\text { - Continuidade na outorga de concessões no setor de eletricidade. } \\
\text { - Inclusão no PND de trechos rodoviários, do Trem de Alta Velocidade (TAV) e de aeroportos; } \\
\text { realizados os leilões das Usinas Hidrelétricas de Santo Antônio e de Jirau, em Rondônia. }\end{array}$ \\
\hline 2011-2015 & Dilma Rousseff & $\begin{array}{l}\text { - Continuidade na outorga de concessões em aeroportos, linhas de transmissão de energia, } \\
\text { TAV e trechos rodoviários. } \\
\text { - Privatização do IRB - Brasil Resseguros. }\end{array}$ \\
\hline
\end{tabular}

Fonte: Elaborado pelas autoras com os dados dos Relatórios de Atividades do Programa Nacional de Desestatização (BNDES, 1992-2015) dos respectivos anos e com dados do site do banco. 
Para Costa e Peci (1999, p. 3), a privatização ou a desestatização (para uma discussão sobre o uso dos dois termos, ver Pachi, 2008a) "se inscreve na história do processo de transformação do Estado brasileiro, ditado também por razões de natureza social e política". Isso porque o movimento de transferência para o setor privado de serviços públicos e atividades industriais originalmente executadas pelo Estado costuma ser enquadrado num contexto político e histórico específico, associado à crise do Estado nacional-desenvolvimentista no plano nacional e à expansão da ideologia neoliberal no plano econômico internacional (Bresser-Pereira, 1998; Fadul, 1999). Nesse contexto, houve "um consenso político de caráter liberal", tendo como base as estratégias "de desenvolvimento dependente e associado; as estratégias neoliberais de estabilização econômica; e as estratégias administrativas dominantes no cenário das reformas orientadas para o mercado" (Paula, 2005, p. 38).

No plano administrativo, houve a emergência da ideologia gerencialista, que passou a ser pervasiva em áreas de atividade fora do setor privado, como em universidades, hospitais e órgãos do setor público (Cherchiglia \& Dallari, 2003; Doolin, 2002; Du Gay \& Salaman, 1996; Onuma, Zwick \& Brito, 2015; Siqueira \& Mendes, 2009). Ainda que Paula (2005) argumente que nos governos Lula e Dilma a chamada administração pública gerencial tenha sido substituída pela administração pública societal, Misoczky, Abdala e Damboriarena (2017, p. 12) contra-argumentam estabelecendo que, mais do que considerar a reforma dos anos 1990 "um episódio historicamente localizado", ela deve ser vista como um projeto sociopolítico "relacionado à etapa neoliberal do capitalismo e ao gerencialismo como seu braço operacional", o que explicaria em parte a permanência da agenda de privatizações em governos de diferentes posições ideológicas, como mostra o Quadro 1.

Na perspectiva da administração, as abordagens sobre as privatizações têm sido predominantemente instrumentais, destacando os ganhos (ou as perdas) de desempenho com a mudança da propriedade pública para a privada (Araújo \& Silvestre, 2014; Bachiller, 2017; Cardoso, Maia, Santos \& Assis Soares, 2013; Fillardi, Leite \& Torres, 2014; Scriptore \& Toneto, 2012; Silvestre, Hall, Matos \& Figueira, 2010) e os impactos na qualidade dos serviços prestados e no atendimento a clientes (Pina, Torres \& Bachiller, 2014; Zilber, Lex \& Ades, 2005). Outras abordagens enfatizam aspectos relativos à mudança organizacional e às relações humanas, como a deterioração nas condições empregatícias (Mccarthy, Reeves \& Turner, 2011; Silva, 2002), a nova gestão de pessoas e as competências requeridas de gestores (Castro, 2005; Luz, 2002; Oliva, 2002), os movimentos de resistência (Palassi, 2002) e as mudanças estratégicas de estrutura (Faria \& Fischer, 2001; Veloso \& Trevisan, 2010), cultura (Ferreira, Fandiño, Segre \& Nascimento, 2010), valores (Luz, 2007) e identidades organizacionais (Carrieri, 2002).

Em que pese a contribuição dessas pesquisas para o entendimento do fenômeno, são poucas aquelas que analisam o papel da mídia na construção de um imaginário social sobre a privatização e o papel do Estado na prestação de serviços públicos. Visto que a história nos mostra o caráter não evolutivo, e sim político-ideológico, na passagem da provisão de serviços do setor público para o privado (Clifton, Lanthier \& Schröter, 2011; Fadul, 1999), torna-se relevante uma melhor compreensão sobre a forma com que imaginários favoráveis ou desfavoráveis à privatização se constroem socialmente. Assim, a mídia, que tem o poder de reafirmar "um imaginário social sobre presente, passado e futuro, no qual os indivíduos de um tempo presente internalizam imagens e referências" (Pachi, 2015, p. 32), desempenha um papel influente sobre a opinião pública ao construir uma interpretação possível sobre as privatizações, justificando-as, legitimando-as e naturalizando-as na sociedade.

No caso da grande imprensa, a discussão sobre o papel da mídia na construção discursiva de fenômenos organizacionais adquire relevância, uma vez que "as principais publicações jornalísticas no 
Brasil, em sua maioria, são de propriedade privada e têm fins lucrativos [vinculando-se] diretamente com outros meios de comunicação e outros setores empresariais" (Smith, 2000, p. 20). Assim, como organizações de natureza pública e privada constituídas desde o início como geradoras de lucros, ampla tiragem e significativa atuação política (Capelato, 2014), os jornais assumem "diferentes posicionamentos, influenciando e dirigindo o cotidiano das pessoas [e publicando] o que elegeu como apropriado de chegar ao público" (Santos \& Costa, 2019, p. 373).

No campo da linguística, pesquisas como as de Pachi (2008a, p. xi, 2008b, 2015) e Leal (2005) adotam a abordagem teórico-metodológica da análise crítica do discurso (ACD) para compreender de que modo a prática discursiva da mídia enquadra "a privatização como marco simbólico de um período de prosperidade", estabelecendo um senso comum favorável à privatização. Na administração pública, pesquisadores dessa tradição vêm se debruçando sobre a expansão da ideologia gerencialista na gestão de pessoas em empresas públicas (Onuma et al., 2015; Siqueira \& Mendes, 2009), sobre o uso da linguagem como forma de exclusão de cidadãos quanto a medidas que afetam a sociedade (Rosa, 2011) e sobre a construção de conhecimento dentro do campo (Wallmeier, Helmig \& Feeney, 2019), ainda que sejam poucas aquelas que enfatizam textos da mídia. $\mathrm{Na}$ administração de empresas, pesquisas com abordagens da ACD têm analisado a mídia em temas como fusões e aquisições (Riad, Vaara \& Zhang, 2012; Vaara \& Monin, 2010), fechamento de unidades organizacionais (Vaara \& Tienari, 2008) e liderança (Elliott \& Stead, 2018; Liu, Cutcher \& Grant, 2017), entre outros.

A presente pesquisa se alinha às mencionadas acima ao perguntar de que maneira a mídia hegemônica e a grande imprensa, em particular, vêm representando a privatização das telecomunicações ao longo dos anos, bem como quais aproximações e afastamentos com mídias que se posicionam claramente a favor ou contra a privatização. Ao contrário dos artigos acima mencionados, o presente texto contribui para o debate sobre privatizações de três maneiras: 1) de um ponto de vista metodológico (como explorado em Baker et al., 2008; Freitas, Biar \& Martins, no prelo), trazendo as abordagens com grandes corpora textuais (chamadas de corpus linguistics, em inglês), que podem desvelar as estratégias para a identificação e a análise de padrões de representação da mídia dificilmente identificáveis a olho nu; 2) analisando, por um período extensivo (de 1994 a 2015), o discurso e as representações da mídia hegemônica sobre as privatizações das telecomunicações brasileiras, tendo como premissa o efeito cumulativo do poder da mídia por meio da repetição de determinadas representações e de formas de causalidade e agência (Baker, 2010); e, por fim, 3) comparando as representações da mídia hegemônica às de mídias posicionadas como pró e antiprivatização, revelando como o discurso da primeira se distancia de outros discursos possíveis sobre o tema.

\section{AS PRIVATIZAÇÕES EM CONTEXTO}

A privatização de empresas estatais brasileiras e, mais especificamente, das telecomunicações brasileiras nos anos 1990 - considerada a "joia da coroa" das empresas estatais brasileiras - costuma ser enquadrada como parte de um movimento mais amplo de cunho internacional que ganhou características próprias no plano nacional, tendo como principal característica a ascensão da ideologia neoliberal como forma de pensar o Estado, seu papel, seu tamanho e seu escopo.

A reforma de Estado efetuada no Brasil nos anos 1990, durante o governo de Fernando Henrique Cardoso (FHC), levava em conta essa ideologia ao propor a redução do tamanho do Estado por meio de privatizações, terceirizações e publicização; a redução da intervenção do Estado a apenas 
o necessário, por meio das desregulamentações; o aumento da governança do Estado por meio de ajuste fiscal e da reforma administrativa rumo a uma administração pública gerencial; e o aumento da governabilidade, com instituições políticas garantidoras da intermediação dos interesses (BresserPereira, 1998, p. 60).

Para Bresser-Pereira, o pai da reforma de Estado de 1995, a crise econômica iniciada nos anos 1970 e que teve seu auge nos anos 1980 teria sido uma crise do Estado

em parte em consequência da incapacidade de reconhecer os fatos novos que ocorriam no plano tecnológico, em parte devido à visão equivocada do papel do Estado como demiurgo social, e em parte, finalmente, porque as distorções de qualquer sistema de administração estatal são inevitáveis à medida que transcorre o tempo (1998, p. 53).

A esse argumento, o autor contrapõe outra crise do sistema econômico, a de 1930, que teria sido uma crise do capitalismo liberal, tendo sua origem no mercado. Essa crise teria levado à ascensão do Estado nacional desenvolvimentista no Brasil e à sua primeira reforma de Estado, com o Estado Novo do governo ditatorial de Getúlio Vargas. A reforma seguinte teria sido durante a ditadura militar, em 1967, já na segunda fase do nacional-desenvolvimentismo no país, e a terceira em 1995, em que se incluem as privatizações das telecomunicações, durante o governo FHC (Costa, 2008).

Autores como Gurgel (2017, pp. 164-165), no entanto, rejeitam o diagnóstico de origem da crise de Estado dos anos 1980 de Bresser-Pereira (1998) ao argumentar que a origem seria tanto o mercado quanto o Estado e que tornar o último culpado pela crise "foi um expediente hábil para poder reduzi-lo, principalmente pela via da transferência de ativos e serviços públicos para o setor privado". Para o autor,

ainda que fosse o discurso corrente, na mídia e na academia, não era a ação perdulária do Estado o motivo das privatizações e concessões. Mas sim o fato de que a grande operação da reforma do Estado consistia em promover a transferência de ativos e serviços ao setor privado para propiciar a revalorização, na economia real, dos capitais superacumulados. A seguir, em anos recentes, emergiram as parcerias público-privadas, em que o Estado propicia não só a oportunidade do investimento, mas seu próprio financiamento, através das agências de fomento, onde pontifica o BNDES.

Assim, a ideologia neoliberal teria perdurado em governos de diferentes posições ideológicas, já que os governos de esquerda de Luiz Inácio Lula da Silva e Dilma Rousseff tiveram como destaque o uso de parcerias público-privadas e de concessões públicas. Misoczky et al. (2017, p. 1) reforçam esse argumento ao definir o neoliberalismo como um "programa político dinâmico e resiliente que organiza a etapa atual do capitalismo, operacionalizado a partir do gerencialismo, uma racionalidade que propõe a reprodução da lógica de mercado em todas as dimensões da vida associada”.

Antes mesmo da reforma de 1995, o governo de Fernando Collor (1990-1992) já se inspirava numa agenda neoliberal com o Plano Nacional de Desestatização (PND), que visava reduzir a dívida pública e promover maior concorrência nacional (Almeida, 2013). Ainda que o Programa Nacional de Desestatização do governo de João Figueiredo (1979-1985) e a venda de empresas que haviam sido nacionalizadas por insolvência durante o governo de José Sarney (1985-1990) já houvessem ocorrido, 
foi no governo Collor que a agenda neoliberal foi incluída com destaque num programa de reformas econômicas de governo (Almeida, 2013). No entanto, foi no governo de FHC (1995-2002) que o PND foi utilizado como um dos principais instrumentos de reforma do Estado, com a privatização de bancos estaduais, de empresas de eletricidade e energia (como a Light), de ferrovias e rodovias, da Companhia Vale do Rio Doce e do setor de telecomunicações (Couto \& Abrucio, 2003).

No plano internacional, a influência neoliberal teria vindo a partir do fim dos anos 1970, com os governos de Margareth Thatcher, no Reino Unido, e Ronald Reagan, no Estados Unidos. Sob o discurso da eficiência, da orientação ao mercado e da melhoria da qualidade dos serviços, diversas empresas estatais, em especial as de infraestrutura, foram desnacionalizadas ou tiveram seus mercados desregulamentados, num contexto internacional marcado pela ascensão da nova direita, pela substituição de uma economia industrial para uma de serviços, pela globalização financeira e pela valorização do indivíduo em detrimento do coletivo (Clifton et al., 2001; Kroeze \& Keulen, 2014).

A diferença entre os planos internacional e nacional foi a imposição de organismos como o Fundo Monetário Internacional (FMI) e o Banco Mundial para que países endividados, como o Brasil, que sofriam crise fiscal e alta inflação, adotassem as recomendações do Consenso de Washington, com sua agenda neoliberal de abertura econômica, ajuste fiscal, desregulamentação de indústrias, privatização de empresas estatais e redução do Estado na economia (Kogut \& MacPherson, 2011). Não à toa, de acordo com Ramamurti (1992), os países onde mais houve privatizações foram aqueles com maiores déficits fiscais, maior dívida externa e maior dependência aos órgãos de financiamento internacional.

Costa e Peci (1999, pp. 1-2) lembram que, ainda que houvesse pelo menos 3 estratégias para o ajuste fiscal - a reforma patrimonial, transferindo ativos para o setor privado, sobretudo por meio de privatizações; a reforma tributária, voltada ao aumento da receita; e a reforma gerencial, dirigida ao aumento da eficiência do gasto público -, "por afirmação ideológica ou por pressão de organismos internacionais, a maioria dos governos do Terceiro Mundo tem optado por realizar reformas patrimoniais". Em especial, a baixa eficiência das empresas estatais de infraestrutura, em vez de ser creditada à crise econômica e ao uso de seus lucros nas contas públicas ou como instrumento de política monetária, passou a ser explicada pela falta de concorrência e pela consequente falta de incentivos à gestão (Almeida, 2014; Clifton et al., 2011). Além disso, em particular para o setor de telecomunicações, as inovações tecnológicas permitiram a convergência das tecnologias de informação e comunicação, eliminando as barreiras à entrada no setor, oferecendo novas oportunidades de negócios ao setor privado, possibilitando a descaracterização da indústria como monopólio natural (Maculan \& Legey, 1996) e forçando outros países, além de Estados Unidos e Reino Unido, a liberalizar sua indústria de telecomunicações para adquirir competitividade internacional (Kornelakis, 2015).

É preciso lembrar que a presença do setor privado em setores de infraestrutura não era inédita. Esses mesmos setores haviam sido originalmente possibilitados pelas alianças de empreendedores e bancos privados, face os altos investimentos e o risco associado a essas atividades, tanto no Brasil quanto em parte da Europa. A presença do Estado se resumia à regulação de preços e à distribuição de concessões (Clifton et al., 2011; Fadul, 1999). Como lembra Fadul (1999), diversos serviços de infraestrutura no Brasil, como limpeza pública, transporte urbano e abastecimento de água, eram praticados nas cidades por empreendedores privados, e serviços como os de eletricidade, transporte rodoviário, correios e telecomunicações, eram oferecidos por empresas estrangeiras. Nas telecomunicações brasileiras, até os anos 1950, a iniciativa privada era a principal responsável pela exploração do serviço de telefonia em estados e municípios, por meio das concessões (Fascina, 2002). 
Dessa forma, toma-se como pressuposto nesta pesquisa uma visão não evolutiva da Reforma de Estado e, por consequência, da transferência de serviços públicos para o setor privado. Compactua-se, assim, com Costa (2009, p. 80), que tem a Reforma do Estado como uma questão política, de escolha coletiva:

Assim, a Reforma não pode ser tratada como uma questão eminentemente técnica, desvinculada dos compromissos das forças políticas da sociedade e dos interesses que se apresentam na arena do Estado, vale dizer, sem consequências políticas importantes. A reforma do Estado suscita questões de natureza distributiva e, portanto, conflitos de interesses entre diferentes grupos sociais.

Se esse for o caso, de que forma governos e sociedade chegaram a um consenso sobre a necessidade das privatizações? No tocante aos governos, para MacPherson (2006), a disseminação da ideologia neoliberal foi resultado de um esforço planejado de economistas da escola de Chicago, já que, no início dos anos 1980, não havia consenso nem entre economistas nem entre gestores públicos sobre o escopo de atuação do Estado. O autor lembra que, antes das privatizações dos anos 1980, apenas a Alemanha e o Chile haviam privatizado algumas empresas públicas. A escola de Chicago, por meio de uma rede global de economistas associados a governos simpatizantes - como no caso do economista Milton Friedman no governo Thatcher -, teria efetivado uma estratégia proativa de disseminação de sua ideologia econômica que acabou se tornando quase consenso entre as principais escolas de economia do mundo.

E em relação à sociedade? Vaara e Tienari (2002, p. 276, tradução nossa), por exemplo, sugerem que fenômenos organizacionais como fusões e aquisições "geram uma necessidade de entender coletivamente o que está acontecendo. Muito desse entendimento coletivo acontece por meio de textos da mídia ou é refletido nele. Os discursos emergentes moldam o entendimento coletivo desses fenômenos complexos". Assim, a mídia detém uma posição de destaque na forma com que temas que afetam a sociedade são (re)produzidos e recebidos por esta.

Pachi (2008a, p. 5) reitera essa posição ao abordar a imprensa hegemônica "como um lugar legitimado socialmente e de produção de um discurso de formação de opinião, que se expande no espaço público", lembrando que "o discurso da imprensa é um dos que são produzidos no espaço público, não se configurando como único nem como 'reflexo de uma realidade'”. Desse modo, destacase o papel da mídia no processo de construção social de fenômenos organizacionais e políticos como as privatizações, tendo como efeito sua justificação, legitimação e naturalização na sociedade.

Vaara e Tienari (2002), por exemplo, analisaram a construção discursiva de fusões e aquisições na Finlândia e identificaram 4 tipos de discursos que a mídia apresenta sobre o fenômeno: racional, cultural, societal e individualista. O primeiro está relacionado à criação de valor para a empresa, em termos financeiros; o segundo, a um processo de confrontação cultural entre duas empresas agora unidas; o terceiro, ao impacto dessas fusões para a sociedade, ao emprego e à perda da soberania nacional - no caso de fusões com empresas estrangeiras -; e o quarto, a personalidades individuais, como os CEOs, simplificando o fenômeno para os leitores. Esses 4 tipos de discursos acabam justificando, naturalizando e legitimando os impactos dessas mudanças organizacionais aos olhos da opinião pública.

Em relação a temas que envolvem a esfera pública, como se dá a transferência de serviços públicos para o setor privado? Pachi (2008a, 2008b, 2015), por exemplo, analisou o discurso sobre a privatização 
das telecomunicações brasileiras dos jornais Folha de S. Paulo e Estado de S. Paulo, para os anos de 1997 e 1998 (ano da privatização). O autor argumenta que a palavra privatização "se inscreve numa memória e se relaciona a uma época em que o Estado revê seu papel no desenvolvimento econômico" (Pachi, 2008a, p. 22). Sua análise revela que a ênfase dada pela imprensa sobre o tema foi a de ruptura entre o passado e o presente, constituindo um evento fundador. A imagem de passado que a imprensa construiu discursivamente sobre o período estatal dessas empresas reforça o discurso da ineficiência, da falta de investimentos, da falta de telefones e da incapacidade de gestão do Estado, levando as telecomunicações ao caos e afetando negativamente a vida dos cidadãos. "Alimenta-se um imaginário de um passado que produziu efeitos negativos para a sociedade, devendo, portanto, ser rejeitado e negado em sua continuidade. Por esta razão, promove-se no discurso uma ruptura com este passado, estabelecendo na privatização o símbolo do novo" (Pachi, 2008b, p. 2). A mídia, dessa forma, desqualifica o passado de telecomunicações do país, centrado na figura da estatal e do papel do Estado como gestor. Pachi (2008a) também mostra que, pelo discurso da imprensa, há uma vinculação do passado e dos amantes deste ao regime militar, tema até pouco tempo controverso e comumente rejeitado pela contemporaneidade. Além dessa associação, há outra, com os países comunistas: "Compara-se o funcionamento da Telebrás ao de uma estatal soviética, significado negativamente neste discurso. [...] Dessa forma, o regime comunista funciona como parâmetro de comparação para o que ocorria no Brasil” (Pachi, 2008a, p. 165). Ambas as associações - regime militar e países comunistas - têm como objetivo dar uma conotação negativa e antiquada ao status quo do setor de telecomunicações brasileiro.

Assim, por meio de uma distinção entre o novo e o velho, a imprensa faz uma construção utópica do futuro, em que supostos benefícios serão realizados para toda a sociedade. Para Pachi (2008b), a criação dessa utopia de futuro possibilita o estabelecimento da privatização como um marco simbólico, sendo o futuro imaginado um argumento a favor das privatizações, normalizando o fenômeno entre os leitores. Com isso, caracteriza-se o passado das telecomunicações como caótico e ineficiente, e o futuro, como promissor e de bem-estar.

De forma semelhante, Leal (2001), analisando o discurso da imprensa sobre as privatizações da Usiminas, da Companhia Vale do Rio Doce e da Telebrás, mostra como a mídia as representa de forma favorável. A autora mostra como as imagens do passado de empresa estatal na imprensa carregam uma conotação negativa, mostrando o "Estado como um elefante e um pai moribundo. O "elefante" dá a ideia de algo lento, pouco funcional, e a imagem de "pai", a de alguém que dá sem nada receber (Leal, 2001, p. 82). A ideia de pai e de elefante que se faz do Estado, assim, vai contra o imaginário de modernidade que as privatizações trariam. Em contrapartida, as manifestações contra as privatizações são representadas pela imprensa de forma negativa, com o uso de palavras como palco, velhos personagens e canastrões, representando "as manifestações como encenações, algo falso. A representação dos manifestantes como velhos personagens acentua o sentido de que são ultrapassados e sugere que já são conhecidos, contumazes. E canastrões traz o sentido de mau desempenho, incompetência" (Leal, 2001, p. 84).

A mídia possibilita a construção de um entendimento coletivo sobre eventos relevantes à sociedade. Jornalistas não só podem construir novos significados para esses eventos, como também reproduzem discursos já existentes ou que se espera ouvir (Vaara, Tienari \& Laurila, 2006). Os efeitos da mídia, ademais, podem ser cumulativos, por meio da repetição de representações como as demonstradas por Pachi (2008b) e Leal (2001). Pachi (2008a), por exemplo, teve como período de análise os anos da 
própria privatização das telecomunicações. De que modo a mídia constrói esses fenômenos de forma cumulativa ao longo do tempo e quais são as diferenças nas construções discursivas de diferentes tipos de mídias é o que abordaremos nesta pesquisa, utilizando uma metodologia que complementa a utilizada por Pachi (2008a, 2008b) e Leal (2001).

\section{ASPECTOS TEÓRICO-METODOLÓGICOS}

O período de análise desta pesquisa sobre as representações discursivas da privatização do setor de telecomunicações pela mídia foi de 1994 até 2018. Como se trata de um período de 24 anos, torna-se adequada a adoção dos métodos de exploração automática de textos, capazes de engendrar uma leitura não linear (Freitas, 2017), ou, ainda, uma leitura distante, tomando emprestado o termo da literatura (Moretti, 2008).

Na leitura não linear, o ponto de vista diferente possibilitado pelo texto descorporificado permite criar correlações não disponíveis pela leitura convencional, de grande frequência ou não. Na leitura distante, a distância como modo específico de conhecimento privilegia relações, padrões e formas ao abrir mão de detalhes. O uso de grandes coleções de texto para uma leitura distante não é considerado um único método, e sim diversos, que são utilizados e selecionados de acordo com as perguntas de pesquisa (Baker, 2010). Em comum, eles teriam procedimentos de análise que utilizam grandes coleções de textos eletrônicos tratados com ferramentas computacionais específicas e que remontam a uma abordagem surgida nos anos 1990 nos estudos linguísticos (McEnery \& Hardie, 2011).

Se, no entanto, o tipo de trabalho linguístico estava inicialmente subordinado sobretudo à dimensão lexicográfica e pedagógica, desde meados dos anos 2000 começam a surgir trabalhos que articulam corpus e sociolinguística (Baker, 2010) e corpus e análise crítica do discurso (ACD) (Baker et al., 2008; Baker, Gabrielatos \& McEnery, 2012; Strom \& Alcock, 2017; Freitas et al., no prelo), e é a essa tradição que nos alinhamos.

Para a sociolinguística, o uso de corpus pode auxiliar em estudos sobre variação sociolinguística, isto é, o fenômeno em que a língua é utilizada de diferentes formas por diferentes usuários. A abordagem pode revelar diferenças e semelhanças no uso por distintos grupos sociais, de forma sincrônica (entre grupos sociais que coexistem) ou diacrônica (referente às variações ao longo do tempo), e a forma com que variáveis como idade, região, classe social e sexo impactam nessas diferenças (Baker, 2010).

Um uso de corpus interessante para a administração pública e para a administração em geral é a combinação com a abordagem interdisciplinar da $\mathrm{ACD}$, já utilizada no campo para entender como a ideologia gerencialista se insere na gestão de recursos humanos de empresas públicas e privadas (Onuma et al., 2015; Siqueira \& Mendes, 2009) ou como a linguagem pode ser usada como instrumento de exclusão de indivíduos com capital cultural e simbólico diferente daquele de autores de textos (Rosa, 2011). A utilização de grandes corpora - que variam de artigos escritos pela mídia, comunicação organizacional, discursos governamentais e até transcrição de entrevistas -, aliada à ACD, pode auxiliar na representatividade das análises feitas, já que a $\mathrm{ACD}$ trabalha com um número reduzido de textos e é, portanto, menos afeita a revelar padrões frequentes e de forma cumulativa que podem representar discursos hegemônicos.

Um artigo importante na área de linguística que advoga essa combinação é o de Baker et al. (2008). Para esses autores, a ACD, assim como o uso de corpora - ambas as abordagens relativamente recentes no campo da linguística -, costuma não ser considerada um único método. A ACD "adota qualquer 
método que seja adequado para realizar os objetivos de determinada pesquisa inspirada em ACD" (Baker et al., 2008, pp. 273-274, tradução nossa).

A particularidade das diferentes abordagens de ACD é a análise do discurso para além do texto em si, debruçando-se não só sobre o uso da linguagem e as escolhas gramaticais reveladoras de ideologias e vieses dos autores, como também sobre a produção e a recepção desses textos, bem como sua inserção nos contextos cultural, social, político e histórico de sua época. Por meio desses níveis de análise, analistas de discurso têm mostrado como a linguagem é utilizada para fins específicos, como representar de forma enviesada refugiados (Baker et al., 2008), imigrantes (Strom \& Alcock, 2017) e manifestantes contra privatizações (Leal, 2005). No nível linguístico, uma forma bastante desvelada por pesquisadores da ACD é a utilização da nominalização, que ocorre quando um autor opta por representar como entidade processos que ocorrem no mundo. Um exemplo é o da frase do ex-ministro britânico Tony Blair citada por Fairclough (2003, p. 13, tradução nossa): "O mundo moderno está sendo varrido pela mudança". Nesse caso, os agentes do processo, como empresas e governo, são omitidos, e a mudança vira uma entidade. Outras análises linguísticas incluem as escolhas lexicais e o uso de figuras de linguagem, como eufemismo, hipérboles e metáforas. Nas pesquisas de Carrieri (2002) e Palassi, e também nas de Carrieri, Leite-da-Silva e Pimentel (2007), por exemplo, o estudo das metáforas utilizadas por funcionários de empresas recém-privatizadas dão pistas sobre as mudanças na identidade organizacional e na propensão à adesão ao movimento sindical. De maneira complementar, os textos são analisados à luz de sua relação com a sociedade, com os contextos em que são produzidos e recebidos - indicando sua interdiscursividade e intertextualidade - e com os contextos cultural, político, histórico e social nos quais se inserem.

Dada a complexidade da ACD, suas abordagens costumam ser essencialmente qualitativas, incluindo um número reduzido de textos (Baker, 2010). Por outro lado, os trabalhos com grandes corpora são quantitativos e executados com auxílio de programas específicos, mas demandam também análises qualitativas, como o exame das linhas de concordância. É assim que, para Baker et al. (2008, p. 283, tradução nossa), grandes corpora podem ser complementares à ACD, já que alguns padrões de uso da linguagem não são distinguíveis a olho nu, isto é, numa leitura convencional: "Uma análise de pequena escala pode não ser capaz de identificar os padrões linguísticos frequentes de forma cumulativa - e, assim, mais propensos a representar discursos de poder - e os menos frequentes podendo constituir discursos de resistência ou minoritários".

Desse modo, padrões linguísticos podem ser revelados "por meio de uma combinação de formas automáticas e qualitativas de análise" que, por sua vez, também podem ser combinadas a análises contextuais como as da ACD (Baker, 2010, p. 123, tradução nossa). Assim como Baker (2010), entendemos que a melhor utilização de grandes corpora é quando esta aperfeiçoa análises qualitativas de pequena escala, e não quando as substitui.

No campo da administração, a análise quantitativa de textos costuma estar associada à análise de conteúdo (Bardin, 1977). No entanto, na articulação entre métodos quantitativos e ACD, distanciamo-nos da proposta de Bardin mais por motivos epistemológicos do que metodológicos, uma vez que compartilhamos procedimentos sistemáticos e de computadores, por exemplo. Por outro lado, analistas de conteúdo confiam em certa transparência da linguagem, na neutralidade das tecnologias e de 
seu papel como auxiliares na introdução de uma "ordem suplementar reveladora de uma estrutura interna" (Bardin, 1977, p. 55).

$\mathrm{Na}$ óptica que assumimos aqui, tecnologias não são neutras - a simples atividade de "contar" palavras já envolve um posicionamento sobre o que deve ser considerado palavra (Anthony, 2013) -, e a dispersão bruta dos dados não é pensada como algo que deve ser arrumado em benefício da norma, mas merece por si uma perspectiva que a privilegie. Com o auxílio das tecnologias, acabamos por introduzir alguma ordem, nem suplementar nem reveladora, mas que permite criar narrativas capazes de jogar luz sobre nossas práticas. Para nós, a categorização não revela, mas constrói (para uma discussão mais aprofundada sobre as diferenças entre as pesquisas com corpus em ACD e a análise de conteúdo, ver Freitas et al., no prelo).

Nesta pesquisa, utilizamos procedimentos familiares à exploração linguística de corpora: geração e análise de lista de palavras, palavras-chave, linhas de concordância e colocação, detalhados a seguir.

A lista de palavras indica a frequência de todas as palavras (ou termos e frases) de um corpus. As palavras mais frequentes de um corpus (de qualquer língua, aliás) são artigos, preposições, verbos auxiliares e certos pronomes que, sozinhos, são considerados semanticamente vazios, sendo chamados de palavras gramaticais. Mas não devem ser eliminadas do corpus, pois, quando combinadas com outras palavras, podem adquirir maior relevância (Pearce, 2014).

Tanto para a lista de palavras quanto para a lista de palavras-chave são utilizados dois indicadores: o de tokens, que aponta o número total de palavras de uma lista, incluindo as repetidas, e o de types, que contabiliza o número de palavras sem repetições desse corpus.

O segundo procedimento é a geração de lista de palavras-chave, que são as palavras (ou grupo de palavras) estatisticamente mais frequentes de um corpus em relação a outro, chamado corpus de controle (corpus de referência ou, ainda, corpus de contraste), utilizado para evidenciar contrastes lexicais entre os diferentes materiais. Ao comparar um corpus a outro, a lista de palavras-chave evidencia a preocupação central do corpus sob análise, o que é chamado de campo lexical. A ideia subjacente é que, por meio da comparação entre os dois corpora com características distintas, o que for específico do material sob análise ficará em destaque. Por isso, as características do corpus de referência influenciarão o que as ferramentas devolvem como palavra-chave, e quanto mais parecidos os corpora, mais chances de elementos relevantes serem filtrados (ou invisibilizados) na geração de palavras-chave.

Ainda que alguns autores aconselhem um corpus de referência 5 vezes maior que o sob análise, estudos recentes mostram que corpora de referência de tamanhos e qualidades variados extraem um conjunto semelhante de palavras-chave, invalidando a exigência anterior (Baker, 2010). Para as análises utilizadas nesta pesquisa, com exceção de quando indicado, o material de contraste foi um corpus com 45 obras do escritor brasileiro Machado de Assis (209.486 tokens e 14.976 types). A escolha desse material como corpus de referência se deu, sobretudo, pela facilidade de acesso aos textos, que estão em domínio público, o que viabiliza a comparação com outros dados e análises.

A análise de palavras-chave foi feita de 3 maneiras. A primeira, na seção de análise de palavraschave, incluiu o levantamento das palavras-chave do somatório de artigos da mídia hegemônica no período de 1994 a 2015. Em seguida, na seção de análise longitudinal das palavras-chave, foi feita uma análise das palavras-chave da mídia hegemônica por mandato presidencial (aproximadamente): 1994 a 1998, 1999 a 2002, 2003 a 2006, 2007 a 2010, 2011 a 2014 e 2015 a 2018. Essa divisão teve como objetivo examinar as diferenças da preocupação central da mídia hegemônica ao longo do tempo. 
Por último, na seção de análise entre mídias, foi feita uma comparação das palavras-chave por tipo de mídia (hegemônica, pró e antiprivatização) entre os anos de 2007 e 2018, de modo a examinar as diferenças entre os elementos centrais de cada uma delas. A razão para a escolha desse período foi a disponibilidade de artigos on-line para as mídias pró e antiprivatização, como pode ser visto na Tabela 2 .

O programa utilizado nesta pesquisa para a manipulação do corpus foi o Antconc 3.5.7 (Anthony, 2016), que calcula as palavras-chave levando em conta a relevância (keyness) e com base no teste estatístico de Log-likelihood, já que dados de linguagem não têm uma distribuição normal. De acordo com Baker (2010), pesquisadores costumam analisar as 20, 50 ou 100 primeiras palavras-chave de um corpus, o que foi obedecido nesta pesquisa.

O terceiro procedimento utilizado foi a análise das linhas de concordância, que nos permitem aproximar o olhar a uma análise mais qualitativa. Com o auxílio da ferramenta, observamos as palavras selecionadas dentro do seu contexto (texto mais próximo), para em seguida ordená-las de acordo com as necessidades da pesquisa. Com isso, é possível identificar padrões de uso de termos não visíveis pelos outros procedimentos.

A busca por colocações foi o último procedimento utilizado e indica a co-ocorrência de duas palavras num corpus, sendo uma o nó - a palavra sob análise - e a outra o termo colocado, que contribui para o significado do nó. A colocação é "uma relação lexical melhor distinguível na análise de grandes volumes de dados e, portanto, menos acessível à análise manual de um número pequeno de textos" (Baker et al., 2008, p. 278). Como os termos colocados não precisam estar adjacentes ao nó para que influenciem no significado do último, são levantados pelo programa num espaço de palavras predefinido, o que permite identificar padrões não sequenciais (McEnery \& Hardie, 2011). Para esta pesquisa, o espaço definido foi o sugerido por Baker et al. (2008), de 5 palavras à esquerda e à direita da palavra nó: "privatização". De igual modo, definimos uma frequência mínima de 10 vezes para a palavra aparecer como "colocado". A estatística utilizada foi a padrão do Antconc, a Mutual Information (MI).

\subsection{Compilação do Corpus}

Para proceder à análise dos discursos sobre a privatização das telecomunicações na mídia, foram compilados 3 corpora. O primeiro, o principal, foi compilado com notícias on-line de mídias de grande circulação, a que chamamos de mídia hegemônica. De acordo com os dados do Instituto Verificador de Circulação (IVC) disponibilizados pelo site Poder360 (2018), os três jornais com maior circulação digital, conforme a Tabela 1, são a Folha de S.Paulo (Folha), O Globo e o Estado de S. Paulo (Estadão). Essas mídias foram consideradas hegemônicas porque, além de serem os principais veículos de comunicação de massa, se declaram apartidárias, primando pela pluralidade de opiniões e pela busca da verdade aos leitores.

O segundo corpus foi construído com notícias on-line do Instituto Liberal, do Instituto Millenium e do Instituto Mises, veículos associados a um perfil econômico liberal, chamado de pró-privatização. O terceiro inclui notícias on-line dos veículos Brasil de Fato e Carta Capital, associados a um perfil econômico mais intervencionista, chamado de antiprivatização. 


\begin{tabular}{|c|c|c|c|c|c|c|c|}
\hline \multirow[b]{3}{*}{ veículo } & \multicolumn{4}{|c|}{$\begin{array}{l}\text { média de exemplares - em milhares } \\
\text { (auditada pelo IVC) }\end{array}$} & \multirow{2}{*}{\multicolumn{3}{|c|}{$\begin{array}{c}\text { evolução -dez. } 2014 \text { a dez. } 2017 \\
\%\end{array}$}} \\
\hline & \multicolumn{2}{|c|}{ dez. 14} & \multicolumn{2}{|c|}{ dez. 17} & & & \\
\hline & impr. & digital & impr. & digital & impr. & digital & total \\
\hline Folha (SP) & 212 & 159 & 121 & 164 & $-42,9 \%$ & $3,3 \%$ & $-23,1 \%$ \\
\hline Globo (RJ) & 205 & 148 & 130 & 113 & $-36,3 \%$ & $-23,9 \%$ & $-31,1 \%$ \\
\hline Super Notícia (MG) & 284 & 39 & 157 & 48 & $-44,9 \%$ & $23,1 \%$ & $-36,7 \%$ \\
\hline Estado (SP) & 163 & 74 & 115 & 89 & $-29,9 \%$ & $19,7 \%$ & $-14,4 \%$ \\
\hline Zero Hora (RS) & 164 & 38 & 101 & 80 & $-38,6 \%$ & $112,6 \%$ & $-10,4 \%$ \\
\hline Estado de Minas (MG) & 56 & 53 & 26 & 25 & $-52,7 \%$ & $-52,1 \%$ & $-52,4 \%$ \\
\hline Correio Braziliense (DF) & 41 & 10 & 26 & 18 & $-35,2 \%$ & $87,2 \%$ & $-11,4 \%$ \\
\hline Valor Econômico (SP) & 43 & 16 & 29 & 29 & $-31,9 \%$ & $83,5 \%$ & $-1,0 \%$ \\
\hline Gazeta do Povo (PR) & 38 & 2 & * & n.d. & * & n.d. & n.d. \\
\hline A Tarde (BA) & 30 & 10 & 17 & 13 & $-44,9 \%$ & $37,9 \%$ & $-24,9 \%$ \\
\hline O Povo (CE) & 19 & n.d. & 14 & n.d. & $-28,2 \%$ & n.d. & $-28,2 \%$ \\
\hline total & 1.256 & 549 & 736 & 580 & $-41,4 \%$ & $5,8 \%$ & $-27,0 \%$ \\
\hline
\end{tabular}

* A "Gazeta do Povo" deixou de circular em versão impressa diária em 2017. O "Povo" não tem dados sobre assinaturas digitais. Fonte: Poder360 (2018), com dados oficiais do IVC (Instituto Verificador de Circulação). Jornais: tiragem média diária + assinaturas digitais.

Nesta análise, construímos um corpus oportunista (McEnery \& Hardie, 2011), construído com o material disponível para atender ao objetivo de pesquisa. Para a compilação automática do material, foi utilizada a ferramenta Bootcat (Zanchetta, Baroni \& Bernardini, 2011), que extrai páginas da internet com base num conjunto de palavras indicadas pelo pesquisador, convertendo-as num corpus em formato de texto. Os conjuntos de palavras foram "privatiza*, telecom*"; "liberaliza*"; "telecom"; "desnacionaliza*, telecom*"; "regulamenta*, telecom*"; "desestatiza*, telecom"; e "regulariza*, telecom ${ }^{\star}$ " . Os arquivos txt gerados foram categorizados manualmente conforme o ano de publicação do artigo e a mídia específica (metadados), sendo "higienizados" quando continham informações publicitárias que dificultavam a análise dos dados.

A Tabela 2 detalha os 3 corpora. Foram calculados types e tokens tanto para a lista de palavras quanto para a lista de palavras-chave. As duas últimas colunas mostram a proporção das palavras-chave em relação ao total de types e de tokens. Para a análise comparativa entre as mídias, foi utilizado o período de 2007 a 2018, já que as mídias pró e antiprivatização só tinham artigos on-line nesse período.

1 Os asteriscos indicam que a palavra em questão pode conter qualquer tipo de terminação. Assim, por exemplo, "telecom*" inclui "telecom", "telecomunicação" e "telecomunicações". 
RAP | Representações discursivas da mídia sobre a privatização das telecomunicações

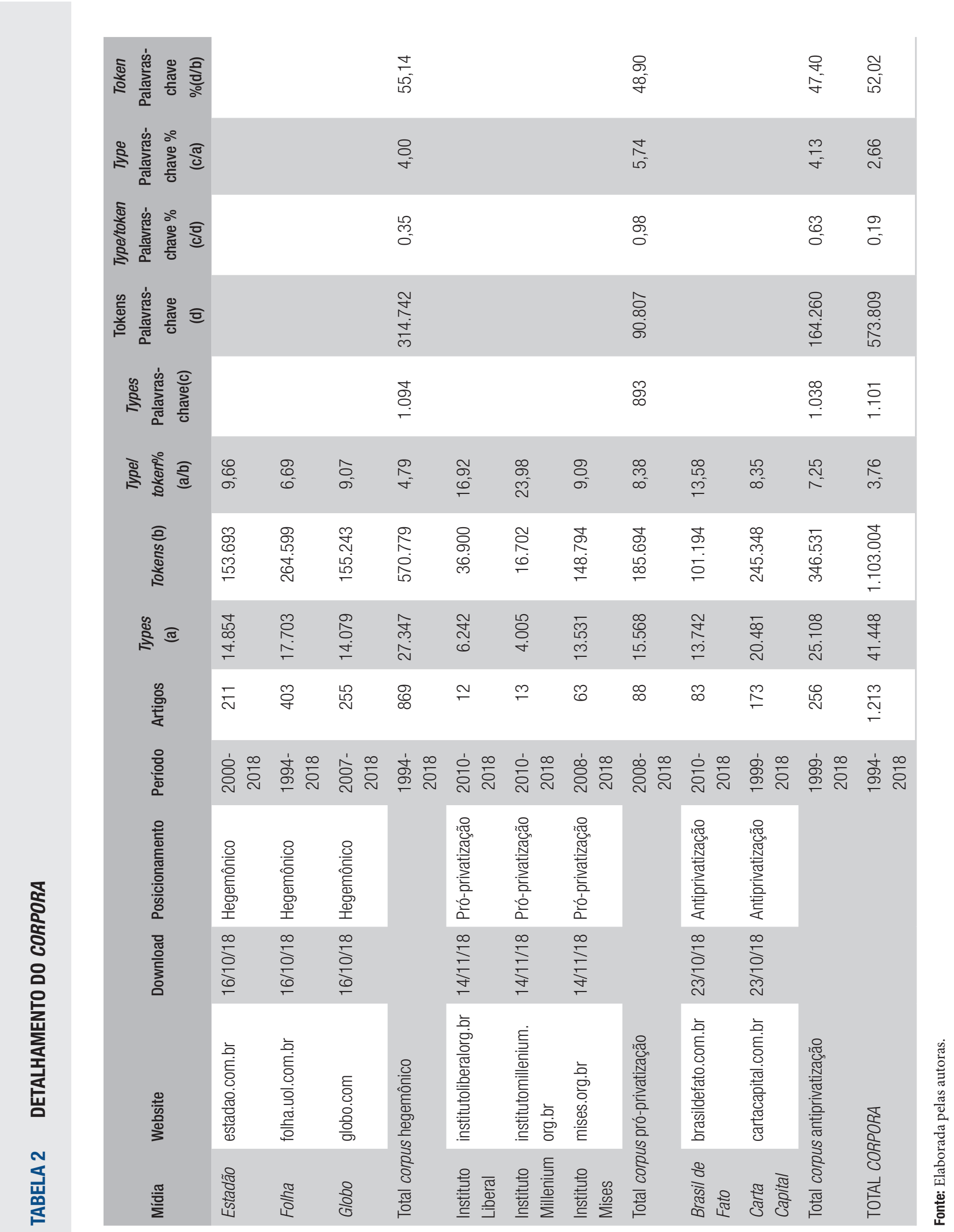

ReVISTA de AdMinistração Pública | Rio de Janeiro 55(3): 559-593, maio - jun. 2021 
RAP | Representações discursivas da mídia sobre a privatização das telecomunicações

\section{ANÁLISE E DISCUSSÃo}

\subsection{Análise de Palavras-chave}

A Tabela 3 mostra as primeiras 50 palavras-chave do corpus, excluídas as palavras gramaticais e palavras como "Folha", "Paulo" (Folha de S.Paulo), "ano", "segundo" e "três", sem relação com a privatização. Algumas dessas palavras foram verificadas quanto ao significado pelas linhas de concordância e análises de cluster, que quantifica palavras compostas no corpus, como Sistema Telebrás e Brasil Telecom. Ilustramos o ponto com a palavra "telecom", que apareceu 762 vezes formando o nome de Brasil Telecom, 543 vezes como Telecom Itália e 412 vezes como Portugal Telecom, além de France Telecom (84) e British Telecom (47), levando à conclusão de que a $1^{\text {a }}$ palavra da lista, “Telecom”, se refere a empresas.

TABELA 3 LISTA DE PALAVRAS-CHAVE MÍDIA HEGEMÔNICA - 1994 A 2018

\begin{tabular}{|c|c|c|c|c|c|c|c|}
\hline N. & Frequência & Keyness & Palavra-chave & N. & Frequência & Keyness & Palavra-chave \\
\hline 1 & 2387 & 1495.19 & Telecom & 26 & 617 & 385.97 & Telebrás \\
\hline 2 & 2472 & 1321.16 & Brasil & 27 & 606 & 379.08 & Opportunity \\
\hline 3 & 2208 & 1273.05 & Empresa & 28 & 646 & 365.93 & Fixa \\
\hline 4 & 1966 & 1194.05 & Empresas & 29 & 582 & 364.06 & Telemar \\
\hline 5 & 1396 & 873.79 & Telefonia & 30 & 558 & 349.04 & Controle \\
\hline 6 & 1346 & 828.67 & $0 \mathrm{i}$ & 31 & 570 & 335.19 & Fundos \\
\hline 7 & 1293 & 809.25 & Bilhões & 32 & 532 & 332.77 & Participação \\
\hline 8 & 1284 & 803.61 & Telecomunicações & 33 & 532 & 332.77 & Telefônica \\
\hline 9 & 1643 & 795.92 & Governo & 34 & 525 & 328.39 & Serviço \\
\hline 10 & 1188 & 719.18 & Mercado & 35 & 520 & 325.26 & BNDES \\
\hline 11 & 1220 & 688.05 & Presidente & 36 & 649 & 323.01 & Ministro \\
\hline 12 & 1062 & 664.56 & $\mathrm{R}(\mathrm{R} \$)$ & 37 & 497 & 310.87 & Operadoras \\
\hline 13 & 1062 & 664.56 & Milhões & 38 & 496 & 310.25 & Internet \\
\hline 14 & 1026 & 642.02 & Privatização & 39 & 496 & 310.25 & Tele \\
\hline 15 & 968 & 605.7 & País & 40 & 506 & 304.68 & Compra \\
\hline 16 & 962 & 601.94 & Ações & 41 & 486 & 303.99 & Agência \\
\hline 17 & 957 & 585.71 & Setor & 42 & 475 & 297.11 & Investimentos \\
\hline 18 & 859 & 537.45 & Celular & 43 & 452 & 282.72 & Operadora \\
\hline 19 & 857 & 536.2 & Anatel & 44 & 468 & 281.06 & Banda \\
\hline 20 & 826 & 493.95 & Banco & 45 & 428 & 267.7 & Federal \\
\hline 21 & 762 & 476.72 & Serviços & 46 & 565 & 253.59 & Portugal (telecom) \\
\hline 22 & 904 & 457.5 & Grupo & 47 & 394 & 246.43 & Acionistas \\
\hline 23 & 753 & 424.05 & US (US\$) & 48 & 582 & 245.35 & Acordo \\
\hline 24 & 651 & 407.25 & Leilão & 49 & 391 & 244.55 & Operação \\
\hline 25 & 621 & 388.47 & (Telecom) Italia & 50 & 390 & 243.92 & Preço \\
\hline
\end{tabular}

Fonte: Elaborada pelas autoras. 
Pela Tabela 3, percebe-se a predominância das empresas e do governo, além da referência aos serviços. Para facilitar a análise, distribuímos as 100 primeiras palavras-chave do corpus hegemônico em 12 categorias, conforme mostrado na Tabela 4, incluindo as palavras gramaticais, que representam $4 \%$ do total de types e $34 \%$ do total de tokens da lista de palavras-chave.

A categorização mostra que o campo lexical da privatização na mídia hegemônica gira em torno das empresas, de seus serviços (telefonia, telecomunicações, celular), do tamanho do negócio (milhões, bilhões, R\$), das atividades relacionadas ao processo de privatização per se (leilão, consórcio, compra, venda, fusão) e de atores governamentais e indivíduos com poder de decisão ou influência sobre o setor (Lula, ministro, presidente).

TABELA 4 CATEGORIAS PARA 100 PALAVRAS-CHAVE DO CORPUS HEGEMÔNICO, 1994 A 2018

\begin{tabular}{|c|c|c|c|c|}
\hline Categoria & Type & $\begin{array}{c}\% \text { total types/ } \\
\text { palavras-chave (a) }\end{array}$ & Tokens & $\begin{array}{c}\% \text { total tokens/ } \\
\text { palavras-chave(a) }\end{array}$ \\
\hline Empresa & 22 & $2 \%$ & 20.028 & $6 \%$ \\
\hline Serviço & 9 & $1 \%$ & 7.393 & $2 \%$ \\
\hline Tamanho & 7 & $1 \%$ & 6.248 & $2 \%$ \\
\hline Processo de privatização & 9 & $1 \%$ & 4.838 & $2 \%$ \\
\hline Governo & 5 & $0 \%$ & 3.442 & $1 \%$ \\
\hline País/ região & 4 & $0 \%$ & 2.631 & $1 \%$ \\
\hline Indivíduo & 4 & $0 \%$ & 2.602 & $1 \%$ \\
\hline Propriedade & 4 & $0 \%$ & 2.446 & $1 \%$ \\
\hline Regulação & 2 & $0 \%$ & 1.343 & $0 \%$ \\
\hline Economia/ negócios & 1 & $0 \%$ & 1.188 & $0 \%$ \\
\hline Outros & 1 & $0 \%$ & 346 & $0 \%$ \\
\hline Palavras gramaticais & 32 & $3 \%$ & 108.305 & $34 \%$ \\
\hline Total 100 primeiras palavras-chave & 100 & $9 \%$ & 160.810 & $51 \%$ \\
\hline Total lista de palavras-chave (a) & 1.094 & $4 \%$ & 314.742 & $55 \%$ \\
\hline Total lista de palavras & 27.347 & & 570.779 & \\
\hline
\end{tabular}

Fonte: Elaborada pelas autoras.

Essa definição do campo lexical pela mídia restringe o tema da privatização à esfera dos negócios, das empresas e de sua relação com o governo. Os indivíduos que aparecem são pessoas públicas, como o presidente do país, os presidentes das empresas de telefonia e o ministro das telecomunicações, limitando as matérias em torno da privatização aos indivíduos com poder de decisão. O interessante é que um dos principais argumentos para a privatização das empresas estatais foi a melhoria da qualidade dos serviços prestados a clientes e a universalização do acesso do cidadão aos serviços de telefonia. As palavras "clientes", "consumidor", "trabalhadores", "funcionários" e "empregos", por exemplo, aparecem como a $110^{\mathrm{a}}$, a $144^{\mathrm{a}}$, a $171^{\mathrm{a}}$, a $188^{\mathrm{a}}$ e a $1.042^{\mathrm{a}}$ palavras na lista, com frequência de 293, 227, 201, 189 e 38, respectivamente. 
Curiosamente, a palavra "universalização" aparece em $498^{\circ}$ lugar, com frequência de 80 . O campo lexical da mídia hegemônica sobre a privatização das telecomunicações, portanto, relega o tema aos negócios, passando ao largo dos interesses mais amplos da sociedade.

É preciso frisar, no entanto, que a análise de corpus permite visualizar padrões de representação sobre palavras ou temas selecionados no que diz respeito à quantidade. $\mathrm{O}$ fato de palavras como "empresa" e "governo" aparecerem com maior frequência no corpus não significa que não existam artigos nele que discutam, por exemplo, a universalização do acesso de serviços de telecomunicações aos cidadãos. Ao contrário, esses artigos existem no corpus. No entanto, enquanto a palavra "universalização" aparece 80 vezes no período de 24 anos, a empresa Oi, por exemplo, aparece 1.346 vezes no mesmo período, sugerindo que a preocupação central da mídia hegemônica ao representar o tema da privatização está nas empresas, e não em seus usuários.

Outro tema que não apareceu em volume significativo na mídia foi a questão do déficit fiscal, lembrando que um dos argumentos para a privatização de empresas era a necessidade de fazer caixa aos cofres públicos. Embora a parte financeira seja bastante importante na mídia, como se pode ver pela categoria "tamanho" na Tabela 3, que inclui as palavras "bilhões", "milhões", "R" (de R\$) e "US" (de US\$), a palavra "fiscal" aparece 78 vezes no corpus, e "dívida pública", 14 vezes. É possível, porém, que a razão seja o longo período de análise, já que, uma vez feita a venda, não haveria por que voltar à questão do déficit por mais 20 anos.

As próximas análises aprofundam os resultados acima de 3 maneiras: 1) com uma análise de palavras-chave dividindo o corpus em subcorpus, de acordo com os períodos correspondentes aos mandatos presidenciais, levantando diferenças marcantes no campo léxico da mídia hegemônica em torno do tema privatização ao longo do tempo; 2) com a análise das palavras-chave de mídias pró e antiprivatização para levantar possibilidades alternativas de representações da privatização; 3) com a análise de colocação da palavra "privatização" na mídia hegemônica.

\subsection{Análise Longitudinal das Palavras-chave}

A análise longitudinal investiga as variações no campo lexical da mídia hegemônica sobre a privatização das telecomunicações de 1994 a 2018, levando em conta as variações ao longo do tempo. O exame foi dividido em 6 períodos, aproximadamente de acordo com os mandatos presidenciais: 1994 a 1998 (ano da privatização), 1999 a 2002, 2003 a 2006, 2007 a 2010, 2011 a 2014 e 2015 a 2018.

A Figura 1 indica a frequência de artigos por ano sobre o tema das privatizações das telecomunicações, por tipo de mídia (hegemônica, pró e antiprivatização). É importante ressaltar que apenas a Folha tinha disponível artigos on-line para todo o período de 1994 a 2018, sendo que as outras mídias apresentam variação no período de cobertura, conforme mostrado na Tabela 2, na seção de aspectos teórico-metodológicos.

Pela Figura 1, pode-se observar que o número de artigos variou ao longo do tempo, apresentando picos em determinadas épocas. O principal pico foi claramente em torno da própria privatização do setor, que ocorreu em julho de 1998, o que justifica o grande número de artigos.

Em 2000, dois anos após a privatização, houve a regulamentação do Fundo de Universalização dos Serviços de Telecomunicações (Fust) e a instituição do Fundo para o Desenvolvimento Tecnológico das Telecomunicações (Funttel). Ademais, vieram à tona disputas entre os sócios do consórcio que comprou a Brasil Telecom, formado pelo banco Opportunity, pela Telecom Itália e por fundos de 
pensão brasileiros referentes ao próprio processo de privatização da Brasil Telecom e à compra da empresa CRT, no Rio Grande do Sul.

O pico seguinte de artigos foi em 2008, quando houve a compra da Brasil Telecom pela concorrente $\mathrm{Oi}$, mediante empréstimos do BNDES. A compra gerou grande celeuma, já que levou a uma mudança no Plano Geral de Outorgas de 1998, a fim de possibilitar a compra de empresa de telefonia fixa por outra - um dos objetivos da privatização era o fim do monopólio e o aumento da concorrência no setor.

Em 2010, o pico no número de artigos se deu graças à venda das ações da Vivo pela Portugal Telecom à Telefónica e a uma aliança da Portugal Telecom com a Oi. Uma das questões discutidas na mídia era a consolidação do mercado em poucos players e a limitação do capital estrangeiro entrando num mercado antes $100 \%$ nacional, grande preocupação do governo do PT na época. A fusão entre Portugal Telecom e Oi só aconteceu mesmo em 2013, o que explica o outro pico nesse ano. No pico posterior, em 2016, acontece a recuperação judicial da Oi, com críticas à criação da chamada "supertele" nacional pelos governos Lula e Dilma.

\section{FIGURA 1 ARTIGOS POR ANO SOBRE PRIVATIZAÇÃO DE TELECOMUNICAÇÕES}

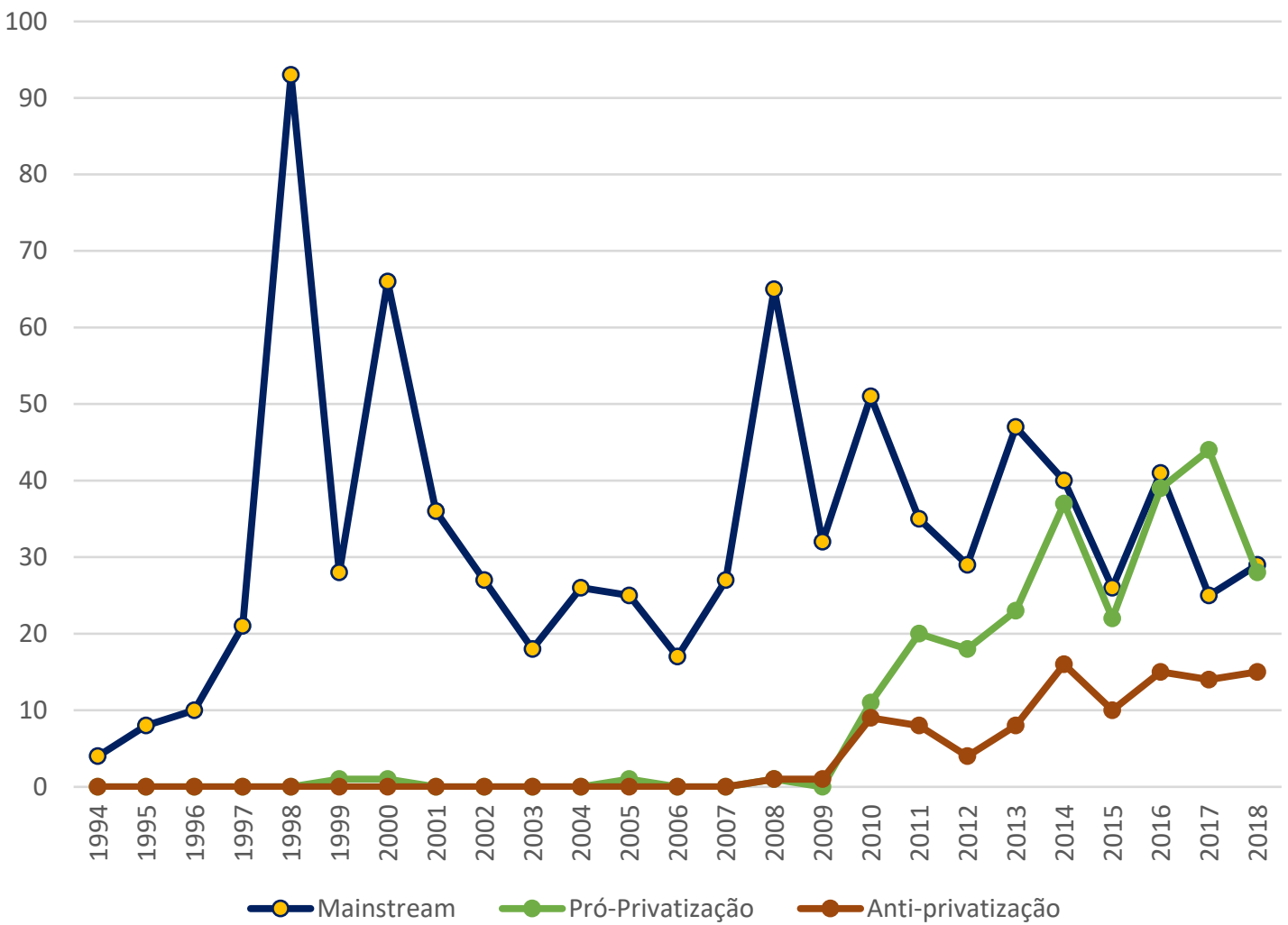

Fonte: Elaborada pelas autoras. 
Para a análise das palavras-chave do corpus hegemônico de 1994 a 2018 por mandato presidencial, colocou-se como corpus de referência o do período anterior, com exceção do primeiro período, quando se manteve o de Machado de Assis. O Quadro 2 detalha o corpus de referência para cada período:

\section{QUADRO 2 CORPUS DE REFERÊNCIA PARA CADA SUBCORPUS TEMPORAL}

\begin{tabular}{ccc} 
N. & Subcorpus hegemônico & Corpus de referência \\
\hline 1 & 1994 a 1998 & Machado de Assis \\
\hline 2 & 1999 a 2002 & Hegemônico 1994 a 1998 \\
\hline 3 & 2003 a 2006 & Hegemônico 1999 a 2002 \\
\hline 5 & 2007 a 2010 & Hegemônico 2003 a 2006 \\
6 & 2011 a 2014 a 2018 & Hegemônico 2007 a 2010 \\
& & Hegemônico 2011 a 2014
\end{tabular}

Fonte: Elaborado pelas autoras.

A Tabela 5 mostra as palavras-chave para o período de 1994 a 1998. Como o período aborda os anos antes da privatização e o próprio ano da privatização, aparecem palavras como "norte" e "leste", que compõem o nome Tele Norte-leste, antigo nome para a Telemar, e "sul", para a Tele Centro-Sul, antiga Brasil Telecom. Também aparecem o Ministro das Comunicações, Luiz Carlos Mendonça de Barros, que substituiu Sérgio Motta durante as privatizações e que posteriormente se envolveu no escândalo da privatização da Tele Norte-Leste - suas conversas telefônicas haviam sido grampeadas e mostravam sua predileção para o consórcio do Opportunity, do banqueiro Daniel Dantas. No geral, no entanto, as palavras-chave giram em torno das mesmas categorias apresentadas na Tabela 4, que inclui o período de 1994 a 2018. 
RAP | Representações discursivas da mídia sobre a privatização das telecomunicações

\section{TABELA 5 LISTA DE PALAVRAS-CHAVE SUBCORPUS HEGEMÔNICO PARA 1994 A 1998}

\begin{tabular}{|c|c|c|c|c|c|c|c|}
\hline N. & Freq. & Keyness & Palavra-chave & N. & Freq. & Keyness & Palavra-chave \\
\hline 1 & 415 & 1083.69 & Empresas & 26 & 119 & 309.12 & setor \\
\hline 2 & 325 & 874.85 & Leilão & 27 & 116 & 292.94 & banco \\
\hline 3 & 314 & 845.2 & Telecom & 28 & 102 & 274.34 & Telefónica \\
\hline 4 & 310 & 834.42 & Privatização & 29 & 101 & 271.65 & BNDES \\
\hline 5 & 295 & 794 & Telebrás & 30 & 98 & 263.58 & controle \\
\hline 6 & 314 & 755.71 & Empresa & 31 & 95 & 255.5 & estatal \\
\hline 7 & 253 & 680.85 & Telecomunicações & 32 & 114 & 252.4 & Sul \\
\hline 8 & 227 & 610.82 & Telefonia & 33 & 123 & 248.91 & grupo \\
\hline 9 & 224 & 602.74 & Celular & 34 & 103 & 245.3 & fixa \\
\hline 10 & 260 & 536.96 & Brasil & 35 & 89 & 239.36 & comunicações \\
\hline 11 & 258 & 512.2 & Governo & 36 & 89 & 239.36 & consórcios \\
\hline 12 & 196 & 506.19 & Mercado & 37 & 118 & 236.55 & sistema \\
\hline 13 & 183 & 492.34 & Tele & 38 & 86 & 231.29 & Anatel \\
\hline 14 & 182 & 489.65 & Bilhões & 39 & 92 & 229.28 & leste \\
\hline 15 & 172 & 462.73 & consórcio & 40 & 113 & 220.5 & Portugal \\
\hline 16 & 160 & 430.43 & Telesp & 41 & 103 & 211.32 & venda \\
\hline 17 & 178 & 401.6 & Ministro & 42 & 78 & 209.77 & participação \\
\hline 18 & 144 & 387.36 & Ações & 43 & 77 & 207.08 & Barros \\
\hline 19 & 159 & 373.93 & Norte & 44 & 75 & 201.7 & (preço) mínimo \\
\hline 20 & 154 & 372.86 & US (\$) & 45 & 75 & 201.7 & telefônica \\
\hline 21 & 129 & 346.99 & Milhões & 46 & 75 & 201.7 & telefônicas \\
\hline 22 & 225 & 343.27 & $R(\$)$ & 47 & 74 & 199.01 & Mendonça \\
\hline 23 & 149 & 342.43 & presidente & 48 & 70 & 188.25 & Italia \\
\hline 24 & 119 & 320.08 & País & 49 & 67 & 180.18 & Embratel \\
\hline 25 & 115 & 309.32 & Preço & 50 & 66 & 177.49 & serviços \\
\hline
\end{tabular}

Fonte: Elaborada pelas autoras.

Comparando o subcorpora de cada período em relação ao anterior, chegamos às diferenças de grupo de palavras estatisticamente mais frequentes em um período do que em outro, conforme a Tabela 6. 
RAP | Representações discursivas da mídia sobre a privatização das telecomunicações

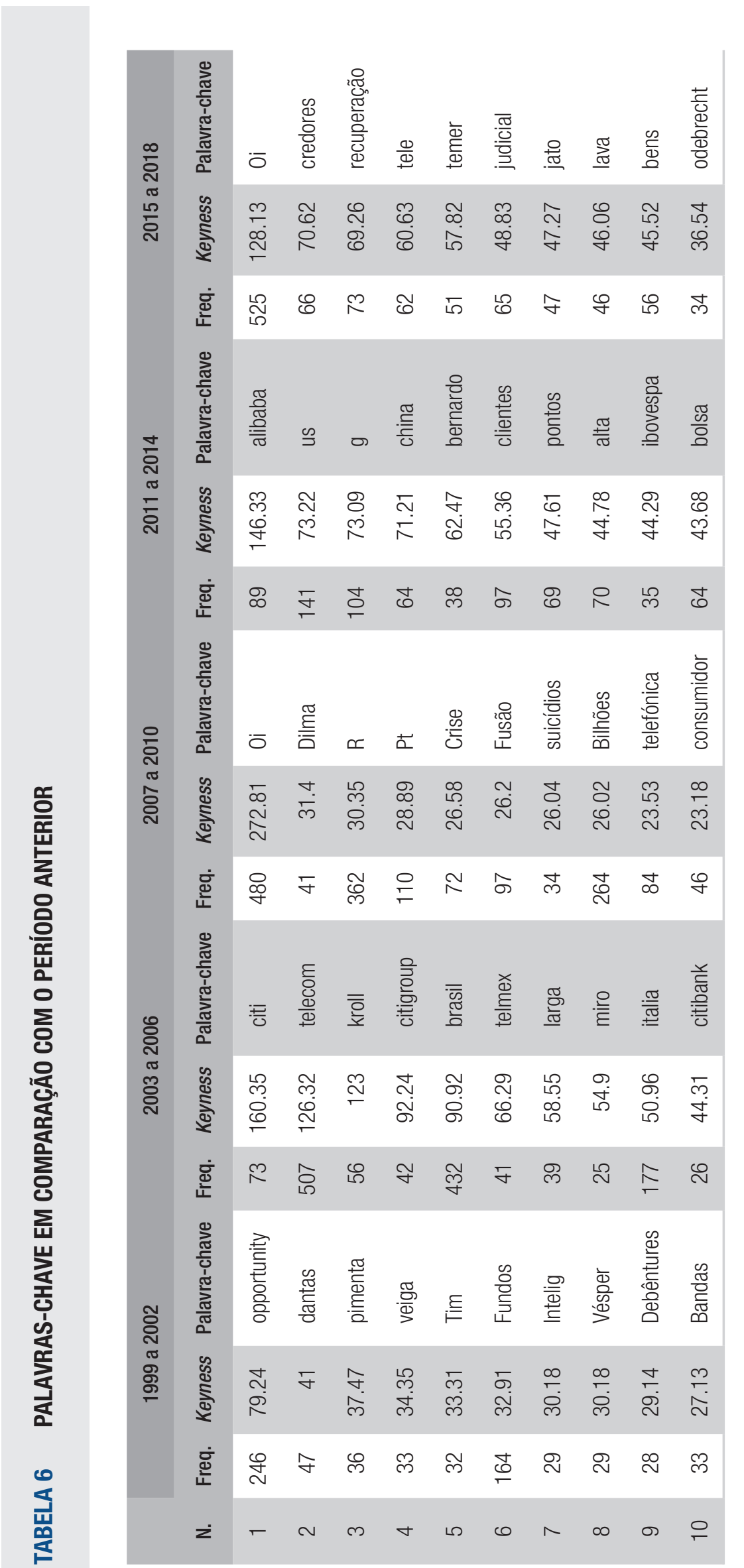


As diferenças entre períodos mostram eventos marcantes de cada época não só para o setor, mas também para o país. De 1999 a 2002, o que aparece em destaque foi o primeiro grande escândalo da privatização das telecomunicações, tendo à frente o economista Daniel Dantas, do banco Opportunity, episódio que envolveu briga entre os sócios (entre eles, a Telecom Italia), a emissão de debêntures da empresa para pagamento das parcelas da compra da Tele Centro-Sul (depois chamada de Brasil Telecom), além de disputas entre os sócios em relação à compra da CRT, empresa gaúcha de telecomunicações. Nesse período, também aparecem os nomes das empresas-espelho Vésper (espelho da Telemar) e Intelig (espelho da Embratel), criadas para fazer concorrência às chamadas incumbentes. No mesmo período, o governo iniciou a venda de novas licenças para as bandas C, D e E de celular.

De 2003 a 2006, outro escândalo envolvendo o banco Opportunity entra em destaque, dessa vez com a contratação da agência de espionagem Kroll por Daniel Dantas para investigar a Telecom Italia, sua sócia na Brasil Telecom. A venda da parte do Citigroup na Brasil Telecom também aparece bastante na mídia, dentro do contexto de desentendimentos entre sócios na Brasil Telecom. Nesse período, a Telmex compra a Embratel da americana MCI/Worldcom, e a internet de alta velocidade, a chamada banda larga, passa a crescer e a constituir um segmento importante no portfólio das empresas de telecomunicações.

O destaque dos períodos posteriores fica com a Telemar, renomeada de Oi, com sua fusão com a Brasil Telecom, a aliança com a Portugal Telecom, além de sua recuperação judicial no período de 2015 a 2018. Houve, ademais, a compra das ações da Vivo pela Telefónica no período de 2007 a 2010.

O primeiro mandato do governo Dilma e o governo de Temer, bem como os escândalos de suas respectivas épocas - como os suicídios de funcionários da France Telecom pós-privatização e a Lava-Jato -, entram como destaques em relação ao período imediatamente anterior. O ministro das Telecomunicações, Paulo Bernardo, aparece na lista de 2011 a 2014, assim como a China, com a abertura do seu mercado gigante de telefonia celular e a oferta pública de ações da empresa chinesa de internet Alibaba.

Nessa análise por período, é interessante observar como as palavras-chave "consumidor" e "clientes" despontam no período de 2007 a 2010 e 2011 a 2014, respectivamente, em relação aos períodos anteriores. Ao analisar qualitativamente as linhas de concordância em torno da palavra "consumidor", para o período de 2007 a 2010, pôde-se verificar que o uso da palavra tinha como contexto a compra da Brasil Telecom pela Oi. A crítica à compra seria a diminuição da concorrência, prejudicando o consumidor. Ademais, as empresas passaram a ser criticadas pelo descumprimento das novas regras de atendimento ao consumidor estabelecidas na época.

Em relação à palavra "clientes", entre 2011 e 2014, a análise qualitativa de concordância revelou que houve um destaque maior a questões como qualidade dos serviços de telefonia - em especial, a celular. Isso porque o crescimento acelerado da base de clientes não havia sido acompanhado dos investimentos necessários por parte das operadoras, incorrendo em punições por parte da Anatel. As mudanças no setor com a fusão da Oi/Portugal Telecom e a compra da Vivo pela Telefónica também mostram a concentração de clientes nessas empresas.

Por que apenas nesses períodos as palavras "clientes" e "consumidores" se mostraram mais significativas do que nos outros? Uma das explicações pode ser o amadurecimento do setor e o aparecimento de questões que afetam a prestação de serviços ao cliente, como a necessidade de investimentos na rede para acompanhar a expansão da base de clientes e as mudanças no perfil de uso, tendo destaque o uso de serviços de dados. Outra explicação pode ser a atuação mais ativa de 
órgãos reguladores como a Anatel e o Procon, assim como a própria criação da Secretaria Nacional do Consumidor em 2012, no governo Dilma.

A análise longitudinal, dessa forma, revela as mudanças ocorridas no setor das telecomunicações pós-privatização e a ênfase dada pela mídia hegemônica às questões surgidas em cada período. Existiriam, no entanto, outras ênfases possíveis sobre os acontecimentos da época relacionados à privatização do setor? A próxima análise trata disso, ao comparar o campo lexical da mídia hegemônica ao de mídias pró e antiprivatização.

\subsection{Análise entre Mídias (Hegemônica, Pró-privatização e Antiprivatização)}

A análise comparando os 3 corpora - hegemônico, pró-privatização e antiprivatização - levou em conta as 100 primeiras palavras-chave de cada grupo para o período de 2007 a 2018. Foi feita, então, uma categorização dessas palavras-chave de cada corpus para facilitar a análise, tendo sido possível manter as categorias de análise da abordagem anterior, o que indica sua pertinência ao campo, sendo necessário apenas acrescentar a categoria "Cliente".

TABELA 7 CATEGORIZAÇÃO DAS 100 PRIMEIRAS PALAVRAS-CHAVE POR MÍDIA (2007 A 2018)

\begin{tabular}{|c|c|c|c|c|c|c|c|c|c|c|c|c|}
\hline \multirow{3}{*}{ Categorias } & \multicolumn{6}{|c|}{ Números absolutos } & \multicolumn{6}{|c|}{ Percentuais de participação (\%) } \\
\hline & \multicolumn{2}{|c|}{ Anti } & \multicolumn{2}{|c|}{ Hegemônico } & \multicolumn{2}{|l|}{ Pro } & \multicolumn{2}{|l|}{ Anti } & \multicolumn{2}{|c|}{ Hegemônico } & \multicolumn{2}{|c|}{ Pro } \\
\hline & Types & Freq. & Types & Freq. & Types & Freq. & Types & Freq. & Types & Freq. & Types & Freq. \\
\hline Empresa & 4 & 1.662 & 19 & 9.117 & 5 & 1.546 & 0,4 & 1,1 & 1,9 & 5,5 & 0,6 & 1,7 \\
\hline Serviço & 19 & 5.646 & 12 & 4.425 & 7 & 1.614 & 1,9 & 3,7 & 1,2 & 2,7 & 0,8 & 1,8 \\
\hline $\begin{array}{l}\text { Processo de } \\
\text { privatização }\end{array}$ & 3 & 706 & 6 & 1.620 & 3 & 628 & 0,3 & 0,5 & 0,6 & 1,0 & 0,3 & 0,7 \\
\hline Governo & 7 & 2.783 & 6 & 1.971 & 6 & 2.056 & 0,7 & 1,8 & 0,6 & 1,2 & 0,7 & 2,3 \\
\hline Tamanho & 2 & 539 & 5 & 2.962 & 2 & 224 & 0,2 & 0,3 & 0,5 & 1,8 & 0,2 & 0,2 \\
\hline Propriedade & 6 & 1.509 & 5 & 1.202 & 12 & 1.951 & 0,6 & 1,0 & 0,5 & 0,7 & 1,3 & 2,1 \\
\hline $\begin{array}{l}\text { Regulação/ } \\
\text { legislação }\end{array}$ & 10 & 2.896 & 4 & 1.071 & 1 & 95 & 1,0 & 1,9 & 0,4 & 0,6 & 0,1 & 0,1 \\
\hline Indivíduo & 3 & 742 & 4 & 1.494 & & & 0,3 & 0,5 & 0,4 & 0,9 & 0,0 & 0,0 \\
\hline $\begin{array}{l}\text { Economia/ } \\
\text { negócios }\end{array}$ & 4 & 836 & 3 & 1.089 & 19 & 3.540 & 0,4 & 0,5 & 0,3 & 0,7 & 2,1 & 3,9 \\
\hline País/região & 5 & 2.470 & 2 & 993 & 3 & 713 & 0,5 & 1,6 & 0,2 & 0,6 & 0,3 & 0,8 \\
\hline Cliente & 1 & 180 & 2 & 390 & 3 & 425 & 0,1 & 0,1 & 0,2 & 0,2 & 0,3 & 0,5 \\
\hline Outros & 5 & 976 & & & 8 & 1.043 & 0,5 & 0,6 & 0,0 & 0,0 & 0,9 & 1,1 \\
\hline
\end{tabular}




\begin{tabular}{|c|c|c|c|c|c|c|c|c|c|c|c|c|}
\hline \multirow{3}{*}{ Categorias } & \multicolumn{5}{|c|}{ Números absolutos } & \multicolumn{7}{|c|}{ Percentuais de participação (\%) } \\
\hline & \multicolumn{2}{|c|}{ Anti } & \multicolumn{2}{|c|}{ Hegemônico } & \multicolumn{2}{|l|}{ Pro } & \multicolumn{2}{|l|}{ Anti } & \multicolumn{2}{|c|}{ Hegemônico } & \multicolumn{2}{|c|}{ Pro } \\
\hline & Types & Freq. & Types & Freq. & Types & Freq. & Types & Freq. & Types & Freq. & Types & Freq. \\
\hline $\begin{array}{l}\text { Palavras } \\
\text { gramaticais }\end{array}$ & 31 & 63.692 & 32 & 56.237 & 31 & 26.840 & 3,1 & 41,3 & 3,2 & 33,9 & 3,5 & 29,6 \\
\hline $\begin{array}{l}\text { Total } 100 \\
\text { palavras- } \\
\text { chave (a) }\end{array}$ & 100 & 84.637 & 100 & 82.571 & 100 & 40.675 & 10 & 55 & 10 & 50 & 11 & 45 \\
\hline $\begin{array}{l}\text { Total } \\
\text { palavras- } \\
\text { chave (b) }\end{array}$ & 1.011 & 154.218 & 1.012 & 166.007 & 893 & 90.807 & 100 & 100 & 100 & 100 & 100 & 100 \\
\hline
\end{tabular}

Fonte: Elaborada pelas autoras.

A Tabela 7 mostra a distribuição das categorias levando em conta as primeiras 100 palavras-chave de cada corpus, tanto em números absolutos quanto em percentuais de participação de cada categoria no total das palavras. Os percentuais indicados na linha (a) das colunas indicam a participação dessas 100 palavras-chave sobre o total da lista de palavras-chave (b).

Uma análise bem simples dessas categorias nos revela que a mídia hegemônica parece dar uma atenção maior às empresas (categoria "Empresa") do que as outras mídias, bem como ao montante das transações efetuadas em torno da privatização (categoria “Tamanho"), pela sua participação no total de palavras-chave. A mídia antiprivatização, por sua vez, parece dar mais ênfase a questões regulatórias e legislativas (categoria "Regulação/Legislação"), ao passo que a mídia pró-privatização enfatiza a questão da propriedade e temas voltados a economia e negócios. Essa análise corrobora os resultados preliminares de Scherling (2014), que analisou como o termo "privatização" é construído linguisticamente em textos de grupos pró e antiprivatização. Em sua análise, o discurso pró-privatização giraria em torno de categorias voltadas a economia, quantificação, individualidade e fatos e argumentos. Essas categorias revelam que o "sucesso" da privatização se dá em relação a números que impactam a economia, e não a população, primando pela escolha individual e pela liberdade de escolha. Em contrapartida, os discursos antiprivatização teriam uma ênfase na cooperação e na coletividade, defendendo os direitos dos indivíduos e os impactos sobre emprego e cortes de salários.

Para confirmar esses resultados, comparamos os corpora pró e antiprivatização em relação ao hegemônico, colocando este como de referência. A Tabela 8 mostra as primeiras 25 palavras-chave estatisticamente mais frequentes nas mídias anti e pró em comparação com a mídia hegemônica. Para essa análise, retiramos as palavras gramaticais. 


\section{TABELA 8 PALAVRAS-CHAVE DE MÍDIAS ANTI E PRÓ-PRIVATIZAÇÃO 2007 A 2018 - CORPUS DE REFERÊNCIA MÍDIA HEGEMÔNICA}

\begin{tabular}{|c|c|c|c|c|c|c|}
\hline \multirow{2}{*}{ N. } & \multicolumn{3}{|c|}{ ANTI-PRIVATIZAÇÃO } & \multicolumn{3}{|c|}{ PRÓ-PRIVATIZAÇÃO } \\
\hline & Freq & Keyness & Palavra-chave & Freq & Keyness & Palavra-chave \\
\hline 1 & 580 & 393.15 & comunicação & 330 & 531.79 & propriedade \\
\hline 2 & 403 & 217.49 & civil & 316 & 481.44 & livre \\
\hline 3 & 674 & 179.5 & lei & 359 & 326.82 & preços \\
\hline 4 & 235 & 173.47 & meios & 285 & 276.23 & concorrência \\
\hline 5 & 228 & 162.85 & mídia & 531 & 192.21 & estado \\
\hline 6 & 338 & 140.82 & sociedade & 90 & 132.51 & teoria \\
\hline 7 & 214 & 124.28 & liberdade & 158 & 130.91 & produção \\
\hline 8 & 165 & 119.48 & constituição & 158 & 121.44 & impostos \\
\hline 9 & 388 & 108.75 & acesso & 150 & 119.59 & privatizações \\
\hline 10 & 274 & 105.85 & marco & 119 & 118.62 & monopólio \\
\hline 11 & 459 & 99.1 & público & 109 & 118.22 & correios \\
\hline 12 & 197 & 97.06 & interesses & 73 & 115.24 & arranjo \\
\hline 13 & 141 & 94.04 & expressão & 149 & 114.49 & privada \\
\hline 14 & 156 & 93.61 & debate & 127 & 110.45 & liberdade \\
\hline 15 & 151 & 88.65 & povo & 173 & 108.33 & bens \\
\hline 16 & 448 & 88.33 & projeto & 238 & 108.25 & estatal \\
\hline 17 & 280 & 88.03 & direitos & 69 & 107.84 & governamental \\
\hline 18 & 73 & 85.36 & democratização & 907 & 106.48 & governo \\
\hline 19 & 148 & 83.34 & obras & 56 & 100.51 & regulamentações \\
\hline 20 & 299 & 80.96 & pública & 614 & 93.03 & mercado \\
\hline 21 & 119 & 79.47 & popular & 206 & 87.43 & estatais \\
\hline 22 & 67 & 77.77 & art (igo da lei) & 48 & 85.15 & indivíduo \\
\hline 23 & 707 & 77.28 & internet & 66 & 79.45 & reguladoras \\
\hline 24 & 183 & 77.06 & regulação & 95 & 76.49 & agências \\
\hline 25 & 334 & 73.59 & poder & 51 & 74.94 & proprietário \\
\hline
\end{tabular}

Fonte: Elaborada pelas autoras. 
Confirmando a análise anterior, as palavras das mídias antiprivatização que se distinguem da mídia hegemônica têm como ênfase maior a questão regulatória e legislativa (projeto de lei, marco civil, constituição, artigo da lei, regulação), o coletivo (sociedade, público, debate, povo, democratização, pública, popular) e os direitos (liberdade de expressão, direitos). Assim, a preocupação dos artigos de mídias antiprivatização parece ser garantir e proteger os direitos da população no que tange à privatização, com ênfase na regulação e na legislação do setor de telecomunicações.

As palavras que distinguem o discurso de grupos pró-privatização, por sua vez, giram em torno de termos econômicos, como "propriedade", "preços", "livre concorrência", "impostos", "monopólio", "liberdade", "produção" e até "teoria", demonstrando o caráter didático dessas mídias ao trazer conceitos econômicos como defesa de uma agenda política. O papel do Estado e da propriedade é bastante discutido, como pode ser visto pelas palavras "estatal", "governamental", "governo" e "privada". À semelhança do discurso anti, o discurso pró também enfatiza mais a questão das regulamentações e do papel das agências reguladoras, mas sem entrar no mérito da lei e da constituição.

Esses resultados remetem aos tipos de discursos da mídia identificados por Vaara e Tienari (2002) sobre fusões e aquisições: o racional, o cultural, o societal e o individualista. A mídia pró se encaixaria no discurso racional, em que a teoria explica racionalmente a necessidade de privatização, ao passo que a mídia anti enfatiza um discurso societal, preocupada sobre as consequências das privatizações na sociedade. Pela análise de corpus, não foi observado nessas mídias nenhum discurso mais cultural sobre as privatizações - o que poderia ocorrer, já que diversas empresas estrangeiras entraram no mercado, além das distinções culturais entre empresa privada e estatal. O discurso individualista, que simplifica o fenômeno por meio de histórias sobre determinados indivíduos, foi observado mais na mídia hegemônica, que enfatiza a ação de indivíduos com poder de decisão no que tange às telecomunicações - o banqueiro Daniel Dantas, os diversos ministros das Comunicações e o próprio presidente da República.

\subsection{Análise de Colocação}

A última análise de corpus foi a análise de colocação. A Tabela 9 mostra os 25 principais termos colocados gerados pelo Antconc para a palavra-nó "privatização". Esse nó tem 114 colocados com frequência de pelo menos 10 vezes, e esses colocados, no total, acontecem 6.530 vezes no corpus hegemônico. A coluna de frequência indica o número de vezes que o colocado aparece junto ao nó (privatização), a coluna de freq. (L) indica o número de vezes que o colocado aparece à esquerda do nó e a coluna freq. $(\mathrm{R})$, o número de vezes que aparece à direita. A coluna stat indica a estatística de cada colocado. 
RAP | Representações discursivas da mídia sobre a privatização das telecomunicações

TABELA 9 COLOCADOS PARA PRIVATIZAÇÃO (5L E 5R)

\begin{tabular}{|c|c|c|c|c|c|}
\hline \multicolumn{6}{|c|}{ Total de colocados (types): 114 - PRIVATIZAÇÃO } \\
\hline \multicolumn{6}{|c|}{ Total de colocados (tokens): 6530} \\
\hline N. & Freq & Freq (L) & Freq $(\mathrm{R})$ & Stat (MI) & Collocate \\
\hline 1 & 19 & 2 & 17 & 772.383 & telebras \\
\hline 2 & 226 & 9 & 217 & 767.081 & telebrás \\
\hline 3 & 108 & 4 & 104 & 706.729 & sistema \\
\hline 4 & 10 & 9 & 1 & 694.983 & pós \\
\hline 5 & 76 & 70 & 6 & 655.711 & desde \\
\hline 6 & 64 & 57 & 7 & 642.976 & após \\
\hline 7 & 68 & 66 & 2 & 627.944 & processo \\
\hline 8 & 34 & 30 & 4 & 627.648 & modelo \\
\hline 9 & 40 & 11 & 29 & 622.252 & teles \\
\hline 10 & 10 & 9 & 1 & 613.791 & leilões \\
\hline 11 & 25 & 23 & 2 & 607.711 & época \\
\hline 12 & 12 & 12 & 0 & 600.428 & participar \\
\hline 13 & 75 & 73 & 2 & 600.206 & leilão \\
\hline 14 & 18 & 15 & 3 & 589.737 & programa \\
\hline 15 & 32 & 28 & 4 & 561.593 & antes \\
\hline 16 & 10 & 10 & 0 & 560.880 & processos \\
\hline 17 & 22 & 5 & 17 & 560.765 & estatais \\
\hline 18 & 41 & 37 & 4 & 551.153 & depois \\
\hline 19 & 18 & 3 & 15 & 547.590 & julho \\
\hline 20 & 10 & 3 & 7 & 544.169 & começou \\
\hline 21 & 21 & 5 & 16 & 531.732 & estatal \\
\hline 22 & 17 & 15 & 2 & 528.836 & durante \\
\hline 23 & 55 & 31 & 24 & 508.894 & anos \\
\hline 24 & 15 & 11 & 4 & 508.413 & partir \\
\hline 25 & 58 & 17 & 41 & 507.536 & setor \\
\hline
\end{tabular}

Fonte: Elaborada pelas autoras.

Como seria de esperar, já que se trata de um corpus sobre a privatização das telecomunicações brasileiras, os colocados mais frequentes são "Telebrás", "sistema”, "processo", “modelo", "teles", "leilões", "estatal", "julho" (mês da privatização) e "setor". Saltam aos olhos, porém, palavras que marcam o tempo, como "pós", "desde”, “após", “época", “antes”, “depois”, "durante”, “anos” e "partir”. 
Analisando os colocados que marcam o tempo (desde, após, época, antes, depois, durante) por meio das 254 linhas de concordância geradas, conclui-se que a privatização vem sendo representada na mídia hegemônica como um marco histórico, a partir do qual todos os eventos posteriores do setor vão ser comparados. Aqui é interessante fazer uma comparação com o estudo de Pachi (2008a, 2008b) sobre o discurso da mídia na época da privatização, sendo essa representada como um evento divisor de águas entre o novo e o velho, entre o caótico e o bem-estar.

Algumas representações, de fato, mostram a "chegada do novo e do moderno" com a privatização:

Antes da privatização das teles, em 1998, o consumidor brasileiro pagava caro por uma linha. O telefone, ao contrário de hoje, era um bem patrimonial. Havia até um mercado paralelo de linhas. Com a venda das companhias para a iniciativa privada, os preços caíram e o acesso ao serviço aumentou significativamente. Na época, estimava-se que a demanda reprimida era de 13,3 milhões de aparelhos. Menos de um terço das casas tinham telefone (Estadão, maio de 2011).

Apenas alguns artigos que fazem um balanço das privatizações (5, 10 e 20 anos após), todavia, falam das melhorias e dos desafios para o setor. Boa parte dos artigos que estabelecem a privatização como um marco o faz para situar grandes negócios ou para dar uma noção temporal sobre relações existentes na indústria, como os exemplos abaixo:

A incorporação da Vivo é o maior negócio do setor desde a privatização. Com essa operação, a Telefônica está adicionando a seu capital social R \$31,1 bilhões, valor de mercado das ações da Vivo. No total, o grupo terá 77 milhões de clientes, sendo 62 milhões vindos da Vivo. É mais do que tem a Oi, agora vice-líder (Folha de S.Paulo, abril de 2011).

A Agência Nacional de Telecomunicações (Anatel) aprovou no dia 18 de dezembro a compra da Brasil Telecom (BrT) pela Oi, considerado o maior negócio do setor dos últimos dez anos, depois da privatização do Sistema Telebrás. A supertele, fruto da fusão entre Oi e BrT, nasce com receita bruta anual de $\mathrm{R} \$ 41$ bilhões, concentra 22 milhões de telefones fixos e quase 30 milhões de celulares (Estadão, dezembro de 2008).

Daniel Dantas, um baiano de 53 anos, está no meio de assuntos polêmicos desde a privatização da Telebrás, em 1998. Meses depois, vieram à tona as escutas telefônicas que flagraram o então ministro das Comunicações Luiz Carlos Mendonça de Barros articulando benefícios ao Opportunity para a privatização - o episódio dos "grampos do BNDES” (O Globo, julho de 2008).

A análise de concordância mostra que a privatização das telecomunicações é ainda vista como um grande marco do setor, servindo como medida para todos os eventos posteriores. Sua utilização como evento fundador varia, às vezes de forma positiva e às vezes de forma negativa, embora a ênfase seja nos negócios gerados pela privatização e nas empresas envolvidas. 


\section{CONCLUSÕES}

O que uma análise de um vasto acervo de notícias pode nos dizer sobre as representações da mídia acerca das privatizações das telecomunicações brasileiras? Ao utilizar a metodologia de exploração linguística de grandes corpora para analisar o discurso da mídia hegemônica sobre o evento, pode-se ter uma ideia de como a mídia relega o assunto ao campo dos negócios, das empresas e da relação dessas com o governo, havendo pouca participação de questões sobre usuários, clientes e, principalmente, população. Essa constatação vai de encontro à alegada "neutralidade" e "pluralidade" das mídias analisadas, o que é relevante sobretudo se levarmos em conta o papel de formador de opinião exercido por elas.

A forma com que esse tipo de mídia constrói o discurso sobre o tema da privatização acaba por ratificar a ideia de que telecomunicações não são mais vistas como um serviço público e, portanto, de responsabilidade do Estado. Igualar as telecomunicações a outros serviços/bens de consumo é uma construção discursiva e não neutra, já que a privatização nem sempre foi consenso, como nos mostra a história. Na época das privatizações, Fadul (1999, pp. 76-77) levantava dúvidas

que merecem reflexão acerca do papel e do lugar que os serviços públicos devem ocupar na economia e na sociedade contemporânea para a qual existem, bem como acerca da missão do Estado de assegurar o cumprimento de certas funções primordiais e a defesa de certos valores sociais, juntamente com a promoção do progresso econômico e social.

Vinte e dois anos após as privatizações, podemos assumir que os textos da mídia hegemônica tiveram seu papel em construir socialmente que o lugar de serviços como as telecomunicações é a arena privada. Ao restringir o campo lexical das privatizações às empresas e aos negócios, a mídia hegemônica transforma e reproduz o discurso de que telecomunicações são um negócio como outro qualquer, descaracterizando sua categorização como serviço público e tornando desnecessária sua discussão e o debate com a sociedade. Essa construção pôde ser percebida quando se confronta o discurso da mídia hegemônica ao de mídias anti e pró-privatização. A primeira, com um discurso societal bem-definido, nos faz questionar sobre tipos de discursos inexistentes (ou pouco existentes) na mídia hegemônica, em especial no que tange às questões regulatórias que envolvem a participação da sociedade civil na sua construção. Nesse discurso, há uma preocupação maior sobre os efeitos da privatização dos serviços de telecomunicações na sociedade. A mídia pró-privatização, por sua vez, sugere outra forma de olhar o fenômeno, claramente com maior ênfase no indivíduo e na sua liberdade (e possibilidade) de opções ao escolher um serviço de telecomunicações, também enfatizando a forma com que o governo regulamenta o setor para que essas escolhas existam.

Ao analisar esses outros discursos, novamente questionamos a própria ideia de "pluralidade" da mídia hegemônica, já que os interesses/pontos de vista dos "consumidores/cidadãos" têm sido pouco contemplados no decorrer destes 20 anos após a privatização do setor. Ao construir uma imagem das privatizações que privilegia o ponto de vista das empresas, e não o da população, a mídia normaliza a agenda de privatização de empresas estatais por parte do governo, limitando o debate e a participação da sociedade nele. Esses resultados corroboram os de Leal (2001), em sua análise sobre o discurso (favorável) da mídia em relação às privatizações.

É inquestionável, no entanto, o estabelecimento da privatização como um marco para o setor. À época da privatização, fazia sentido a mídia construir uma imagem de futuro para legitimar a 
desnacionalização dessas empresas, conforme argumentado por Pachi (2008a, 2008b, 2015). No entanto, os desdobramentos da privatização refletiram também mudanças políticas no país, intricando as relações entre o governo e as empresas e, consequentemente, refletindo na representação da mídia hegemônica sobre o setor.

Pesquisas futuras podem utilizar esse mesmo corpus para a identificação de mudanças de padrões de representação conforme a mudança de governo. A alternância dos governos de diferentes posições ideológicas pode ter alterado a forma com que a mídia representou a privatização, de modo mais crítico ou mais efusivo, conforme suas predileções ideológicas.

Uma das principais contribuições do artigo é metodológica, trazendo estratégias da análise linguística feita com grandes corpora para os estudos organizacionais e a administração pública. Estudos críticos sobre fenômenos organizacionais costumam ser qualitativos, enfocando métodos como a ACD para desvelar ideologias por trás dos discursos organizacionais. $\mathrm{O}$ uso de grandes acervos textuais pode mostrar a forma cumulativa com que esses discursos vão sendo propagados e reproduzidos não só pela mídia, como também pela comunicação organizacional, por órgãos de governo, por partidos políticos, entre outros. Além disso, ao longo do trabalho, utilizamos ferramentas (o AntConc e o BootCat) e recursos (o corpus de contraste) de uso público e gratuito. Assim, acreditamos contribuir para a divulgação desse tipo de abordagem.

O estudo também mostra como a mídia deve ser incluída como parte da arena pública e organizacional, em que discursos de fenômenos que atingem a sociedade são legitimados e reproduzidos dentro dela. Se por um lado os resultados não são novos, por outro essa mesma previsibilidade sinaliza a confiança na metodologia utilizada, que pode ser usada em outras questões no âmbito organizacional. Boa parte da pesquisa na área de administração toma como fonte documentos textuais, como relatórios, discursos e leis. A possibilidade de analisá-los sob outro ponto de vista, simultaneamente quantitativo e qualitativo, deve ser capaz de levantar novas questões e responder a questões clássicas de maneiras diferentes. 


\section{REFERÊNCIAS}

Almeida, M. P. (2013). A privatização estruturada: o PND no Governo Collor (1990-1992). Outros Tempos-Pesquisa em Foco-História, 10(16), 65-87.

Almeida, M. P. (2014). A reestruturação do setor público estatal brasileiro rumo às privatizações dos anos 1990. Anos 90, 21(39), 363-397.

Anthony, L. (2013). A critical look at software tools in corpus linguistics. Linguistic Research, 30(2), 141-161.

Anthony, L. (2016). AntConc (Version 3.5.7) [Windows]. Tokyo, Japan: Waseda University. Recuperado de http://www.laurenceanthony.net/ software/antconc/

Araújo, J. F. F. E., \& Silvestre, H. C. (2014). As parcerias público-privadas para o desenvolvimento de infraestrutura rodoviária: experiência recente em Portugal. Revista de Administração Pública, 48(3), 571-593.

Bachiller, P. (2017). A meta-analysis of the impact of privatization on firm performance. Management Decision, 55(1), 178-202.

Baker, P. (2010). Sociolinguistics and corpus linguistics. Edinburgh, Scotland: Edinburgh University Press.

Baker, P., Gabrielatos, C., Khosravinik, M., Krzyżanowski, M., McEnery, T., ... Wodak, R. (2008). A useful methodological synergy? Combining critical discourse analysis and corpus linguistics to examine discourses of refugees and asylum seekers in the UK press. Discourse \& Society, 19(3), 273-306.

Baker, P., Gabrielatos, C., \& McEnery, T. (2012). Sketching Muslims: A corpus driven analysis of representations around the word 'Muslim'in the British press 1998-2009. Applied Linguistics, 34(3), 255-278

Bardin, L. (1977). Análise de Conteúdo. Lisboa, Portugal: Edições 70.

Banco Nacional de Desenvolvimento Econômico e Social. (1992-2015). Programa Nacional de Desestatização: relatório de atividades. Rio de Janeiro, RJ: Autor.

Banco Nacional de Desenvolvimento Econômico e Social. (2020). Histórico/Processos Encerrados/
Desestatização/Transparência. Recuperado de https://www.bndes.gov.br/wps/portal/site/home/ transparencia/desestatizacao/processos-encerrados/ Historico

Bresser Pereira, L. C. (1998). A reforma do Estado dos anos 90: lógica e mecanismos de controle. Lua Nova: Revista de cultura e política, 45, 49-95.

Capelato, M. H. (2014). História do tempo presente: a grande imprensa como fonte e objeto de estudo. In L. A. N. Delgado, \& M. M. Ferreira (Org.), História do Tempo Presente. Rio de Janeiro, RJ: FGV Editora.

Cardoso, V. I. D. C., Maia, A. B. G. R., Santos, S. M. D., \& Assis Soares, F. (2013). O impacto da privatização no desempenho econômico: um estudo em empresas brasileiras de grande porte. Revista Ibero Americana de Estratégia, 12(3), 183-211.

Carrieri, A. D. P. (2002). A transformação das identidades uma empresa de telecomunicações antes e depois de sua privatização: um estudo de metáforas. Organizações \& Sociedade, 9(23), 1-29.

Castro, C. S. D. (2005). Gestão de recursos humanos no setor de telecomunicações: novas empresas, novas práticas? Revista de Administração de Empresas, 45(SPE), 36-47.

Cherchiglia, M. L., \& Dallari, S. G. (2003). A reforma setorial do Estado brasileiro na década de 1990: eficiência e privatização? Um estudo num hospital público universitário. Revista de Administração Pública, 37(2), 313-334.

Clifton, J., Lanthier, P., \& Schröter, H. (2011). Regulating and deregulating the public utilities 1830-2010. Business History, 53(5), 659-672.

Costa, F. L. D. (2008). Brasil: 200 anos de Estado; 200 anos de administração pública; 200 anos de reformas. Revista de Administração Pública, 42(5), 829-874.

Costa, F. L. D. (2009). Bases Teóricas e conceituais da reforma dos anos 1990: crítica do paradigma gerencialista. Revista Brasileira de Administração Política, 2(2), 79-103.

Costa, F. L. D. \& Peci, A. (1999). Desestatização como estratégia de reforma do Estado: Análise preliminar da privatização no Brasil da Nova República. Revista de Administração Pública, 33(3), 191-205. 
Couto, C. G., \& Abrucio, F. (2003). O segundo governo FHC: coalizões, agendas e instituições. Tempo Social, 15(2), 269-301.

Doolin, B. (2002). Enterprise discourse, professional identity and the organizational control of hospital clinicians. Organization studies, 23(3), 369-390.

Du Gay, P., Salaman, G., \& Rees, B. (1996). The conduct of management and the management of conduct: Contemporary managerial discourse and the constitution of the 'competent'manager. Journal of Management Studies, 33(3), 263-282.

Elliott, C., \& Stead, V. (2018). Constructing women's leadership representation in the UK press during a time of financial crisis: Gender capitals and dialectical tensions. Organization Studies, 39(1), 19-45.

Esposito, I. R. (2017, agosto 23). Governo anuncia 57 projetos de concessões e privatização de empresas públicas. Agência Brasil. Recuperado de https://agenciabrasil.ebc.com.br/economia/ noticia/2017-08/governo-anuncia-57-projetos-deprivatizacao-de-empresas-publicas-e

Fadul, É. M. C. (1999). Reforma do Estado e serviços públicos: transformação de um modelo ou adaptação a uma nova ordem social? Revista de Administração, 34(1), 70-78.

Fairclough, N. (2003). Analysing discourse: Textual analysis for social research. London, UK: Routledge.

Faria, L. D. O., \& Fischer, T. (2001). Privatização, mudança \& evolução da estrutura organizacional em três momentos: Tebasa, Telebahia e Telemar. Organizações \& Sociedade, 8(21), 59-75.

Fascina, A. (2002). De Alexandre Graham Bell à Anatel. Pensamento \& Realidade, 5(11), 48-61.

Fernandes, A., \& Tomazelli, I. (2019, novembro 01). Governo busca acelerar processos de privatização. Estadão. Recuperado de https://economia.estadao. com.br/noticias/geral,governo-busca-acelerarprocessos-de-privatizacao,70003072050

Ferreira, E. C. D. V., Fandiño, A. M., Segre, L., \& Nascimento, R. P. (2010). Privatização e mudanças organizacionais: um estudo de caso sobre transformação cultural e comportamental. Cadernos EBAPE.BR, 8(3), 468-491.
Filardi, F., Leite, A. L. D. S., \& Torres, A. A. G. (2014). Análise de resultados de indicadores de gestão e de regulação após a privatização: estudo de caso da Light Serviços de Eletricidade. Revista de Administração, 49(1), 18-32.

Freitas, C. (2017). Estudos linguísticos e Humanidades digitais: corpus e descorporificação. Gragoatá, 22(44), 1207-1227.

Freitas, C., Biar, L., \& Martins, F. (No prelo). Construções do feminino na literatura brasileira: discurso, grandes corpora e leitura não-linear. Revista Brasileira de Linguística Aplicada.

Gurgel, C. R. M. (2017). Para Além da Reforma do Estado-crises e limites da razão liberal. Administração Pública e Gestão Social, 9(3), 159-170.

Kogut, B., \& Macpherson, J. M. (2011). The mobility of economists and the diffusion of policy ideas: The influence of economics on national policies. Research Policy, 40(10), 1307-1320.

Kornelakis, A. (2015). European market integration and the political economy of corporate adjustment: OTE and Telecom Italia, 1949-2009. Business History, 57(6), 885-902.

Kroeze, R., \& Keulen, S. (2014). The managers' moment in Western politics: The popularization of management and its effects in the 1980s and 1990s. Management \& Organizational History, 9(4), 394413.

Lacerda, N. (2020, abril 08). Estatal na lista de privatizações de Bolsonaro é essencial para renda emergencial. Brasil de Fato. Recuperado de https:// www.brasildefato.com.br/2020/04/08/estatal-dalista-de-privatizacoes-de-bolsonaro-e-essencialpara-renda-emergencial

Leal, M. C. D. (2005). O discurso jornalístico sobre privatizações e protestos nas ruas. DELTA: Documentação de Estudos em Lingüística Teórica e Aplicada, 21(SPE), 73-92.

Liu, H., Cutcher, L., \& Grant, D. (2017). Authentic leadership in context: An analysis of banking CEO narratives during the global financial crisis. Human Relations, 70(6), 694-724.

Luz, T. R. (2002). Telemar-Minas: a reinvenção dos gestores. Revista Economia \& Gestão, 2(3), 56-73. 
Luz, T. R. (2007). Valores do Livre Mercado e seus Impactos no Trabalho Gerencial: O Caso TelemarMinas. Gestão e Sociedade, 1(1), 1-22.

Macpherson, J. M. (2006). Palace wars and privatization: Did Chicago Beat Cambridge in influencing economic policies. European Management Review, 3(3), 190-198.

Maculan, A. M., \& Legey, L. R. (1996). As experiências internacionais de regulação para as telecomunicações e a reestruturação dos serviços no Brasil. Revista de Economia Política, 16(4), 67-86.

McCarthy, D. C., Reeves, E., \& Turner, T. (2011). Changing the Rules of the Game: The impact of privatization on firm industrial relations. Public Management Review, 13(6), 845-860.

McEnery, T., \& Hardie, A. (2011). Corpus linguistics: Method, theory and practice. Cambridge, UK: Cambridge University Press.

Misoczky, M. C., Abdala, P. R. Z., \& Damboriarena, L. (2017). A trajetória ininterrupta da reforma do aparelho de Estado no Brasil: continuidades nos marcos do neoliberalismo e do gerencialismo. Administração Pública e Gestão Social, 9(3), 184-193.

Moretti, F. (2008). Distant reading. New York, NY: Verso Books.

Oliva, E. D. C. (2002). A privatização de empresas siderúrgicas brasileiras: reflexos na gestão de recursos humanos. Revista de Administração Contemporânea, 6(1), 141-161.

Onuma, F. M. S., Zwick, E., \& Brito, M. J. (2015). Ideologia gerencialista, poder e gestão de pessoas na administração pública e privada: uma interpretação sob a ótica da análise crítica do discurso. Revista de Ciências da Administração, 17(42), 106-120.

Pachi, F. F., F. (2008a). Privatizar para tornar" público": uma análise do discurso sobre a privatização das telecomunicações em jornais (Tese de Doutorado). Universidade Estadual de Campinas, Campinas, Brasil.

Pachi, F. F., F. (2008b). O passado e a necessidade de ruptura no discurso da imprensa sobre a privatização das telecomunicações. Revista de Letras, 10, 1-19.

Pachi, F. F., F. (2015). A construção do futuro no discurso sobre a privatização das telecomunicações na imprensa. Línguas \& Letras, 16(32), 30-50.
Palassi, M. P. (2002). Privatização e enfrentamento: elementos integradores e desintegradores da resistência coletiva. Revista de Administração Pública, 36(3), 433-461.

Palassi, M. P., Carrieri, A. D. P., Leite-da-Silva, A. R., \& Pimentel, T. D. (2007). Os discursos e as metáforas na análise da propensão à participação: um estudo em um banco privatizado. Revista de Administração Pública, 41(3), 443-473.

Paula, A. P. P. D. (2005). Administração pública brasileira entre o gerencialismo e a gestão social. Revista de Administração de Empresas, 45(1), 36-49.

Pearce, M. (2014). Key function words in a corpus of UK election manifestos. Linguistik online, 65 (3), 23-44.

Pina, V., Torres, L., \& Bachiller, P. (2014). Service quality in utility industries: the European telecommunications sector. Managing Service Quality: An International Journal, 24(1), 2-22.

Poder 360. (2018, janeiro 31). Tiragem impressa dos maiores jornais perde 520 mil exemplares em 3 anos. Recuperado de https://www.poder360.com. $\mathrm{br} /$ midia/tiragem-impressa-dos-maiores-jornaisperde-520-mil-exemplares-em-3-anos/

Ramamurti, R. (1992). Why are developing countries privatizing?. Journal of International Business Studies, 23(2), 225-249.

Resende, S. (2019, novembro 06). Alcolumbre diz que resistência à privatização da Eletrobras é 'muito grande' no Senado. G1. Recuperado de https:/g1.globo.com/politica/noticia/2019/11/06/ alcolumbre-diz-que-resistencia-a-privatizacao-daeletrobras-e-muito-grande-no-senado.ghtml

Revista Época. (2019, novembro 08). Se não privatizar a Eletrobras, será um crime contra o governo brasileiro', diz secretário. Recuperado de https:// epocanegocios.globo.com/Brasil/noticia/2019/11/ se-nao-privatizar-eletrobras-sera-um-crime-contrao-governo-brasileiro-diz-secretario.html

Riad, S., Vaara, E., \& Zhang, N. (2012). The intertextual production of international relations in mergers and acquisitions. Organization Studies, 33(1), 121-148.

Rosa, D. D. S., F. (2011). Poder simbólico no reajuste tarifário do transporte metropolitano de 
passageiros de Porto Alegre na crise de 2004. Revista de Administração Pública, 45(3), 643-668.

Santos, C. A. S., \& Costa, A. S. M. (2019). Imprensa, Discurso Ideológico e Golpe de Estado: uma Análise Crítica do Discurso. Revista Eletrônica de Ciência Administrativa, 18(3), 371-393.

Scherling, J. (2014). (Neo)Liberalizing the state: Privatization of core government social competences - A CDA approach. In Anais do CADAAD 2014, ELTE University, Budapest, Hungary.

Scriptore, J. S., \& Toneto, R., J. (2012). A estrutura de provisão dos serviços de saneamento básico no Brasil: uma análise comparativa do desempenho dos provedores públicos e privados. Revista de Administração Pública, 46(6), 1479-1504.

Silva, J. C. (2002). A reestruturação produtiva no setor bancário em Santa Catarina. Revista de Ciências da Administração, 4(8), 1-13.

Silvestre, B. D. S., Hall, J., Matos, S., \& Figueira, L. A. P. D. A. (2010). Privatização: bom ou ruim? Lições do setor de distribuição de energia elétrica do nordeste brasileiro. Revista de Administração de Empresas, 50(1), 94-111.

Siqueira, M. V. S., \& Mendes, A. M. (2009). Gestão de pessoas no setor público e a reprodução do discurso do setor privado. Revista do Serviço Público, 60(3), 241-250.

Smith, A. M. (2000). Um acordo forçado: o consentimento da imprensa à censura no Brasil. Rio de Janeiro, RJ: Editora FGV.

Strom, M., \& Alcock, E. (2017). Floods, waves, and surges: the representation of Latin@ immigrant children in the United States mainstream media. Critical Discourse Studies, 14(4), 440-457.
Vaara, E., \& Monin, P. (2010). A recursive perspective on discursive legitimation and organizational action in mergers and acquisitions. Organization Science, 21(1), 3-22.

Vaara, E., \& Tienari, J. (2002). Justification, legitimization and naturalization of mergers and acquisitions: A critical discourse analysis of media texts. Organization, 9(2), 275-304.

Vaara, E., \& Tienari, J. (2008). A discursive perspective on legitimation strategies in multinational corporations. Academy of Management Review, 33(4), 985-993.

Vaara, E., Tienari, J., \& Laurila, J. (2006). Pulp and paper fiction: On the discursive legitimation of global industrial restructuring. Organization Studies, 27(6), 789-813.

Veloso, E., \& Trevisan, L. (2010). Estratégias Organizacionais e Processos de Fusão: Estudo de Caso Sobre Mudanças de Estrutura em Agências Bancárias. Revista Administração em Diálogo, 12(3), 60-79.

Wallmeier, F., Helmig, B., \& Feeney, M. K. (2019). Knowledge construction in public administration: A discourse analysis of public value. Public Administration Review, 79(4), 488-499.

Zanchetta, E., Baroni, M., \& Bernardini, S. (2011, julho). Corpora for the masses: the BootCaT front-end. In Pecha Kucha Presented at the Corpus Linguistics 2011 Conference, University of Birmingham, Birmingham, UK.

Zilber, M. A., Lex, S., \& Ades, C. (2005). As privatizações e o novo modelo do setor elétrico brasileiro: o impacto sobre o atendimento das necessidades do consumidor. Gestão \&Regionalidade, 21(61), 51-63. 


\section{Patricia Ayumi Hodge}

https://orcid.org/0000-0003-3229-2573

Doutoranda em Administração no IAG/Escola de Negócios da PUC-Rio. E-mail: ayumihodge@gmail.com

\section{Cláudia Freitas}

https://orcid.org/0000-0001-6807-8558

Doutora em Letras; Professora no PPGEL/Departamento de Letras da PUC-Rio.

E-mail: claudiafreitas@puc-rio.br

\section{Alessandra de Sá Mello da Costa}

\section{https://orcid.org/0000-0003-3207-2888}

Doutora em Administração; Professora no IAG/Escola de Negócios da PUC-Rio.

E-mail: alessandra.costa@iag.puc-rio.br 